\title{
Os Modelos PENS e GameFlow na Avaliação da Satisfação do Jogador: Uma Análise com o Jogo “Caixa de Pandora” Mobile
}

\author{
Title: The PENS and GameFlow Models to Assess Player Satisfaction: An Analysis with the \\ Game “Caixa de Pandora” Mobile
}

\author{
Zildomar Carlos Felix \\ Univ. Federal Rural de Pernambuco \\ zildomar.felix@ufrpe.br
}

Ana Tereza Medeiros C. Silva

Universidade Federal da Paraíba

anaterezaprof@gmail.com
Liliane dos Santos Machado

Universidade Federal da Paraíba

liliane@di.ufpb.br

Luana Rodrigues de Almeida

Universidade Federal da Paraíba

luanaralmeida02@gmail.com

\author{
Júlio Raphael O. Silva \\ Universidade Federal da Paraíba \\ jraphael@eng.ci.ufpb.br
}

\begin{abstract}
Resumo
Mensurar a qualidade da experiência do jogador vem sendo objeto de estudo da comunidade de desenvolvimento de jogos digitais. Neste sentido, entender a experiência do jogador nos jogos com propósitos educacionais têm sido um campo de pesquisa desafiador. A satisfação percebida pelo jogador a partir da sua experiência vem se configurando como um dos meios para potencializar o engajamento em jogos, principalmente quando se trata de jogos com propósito. Este artigo apresenta a avaliação do jogo Caixa de Pandora Mobile após o processo de redesign de uma versão anterior. O objetivo do trabalho foi primeiro verificar se existia diferença significativa na satisfação dos jogadores a partir da aplicação dos modelos GameFlow e PENS e, posteriormente, verificar a satisfação percebida do jogador em relação ao progresso do seu conhecimento no conteúdo enquanto jogava. Os resultados estatísticos mostraram que mesmo utilizando modelos com abordagens distintas, a avaliação não apresentou diferença significativa nos resultados, sugerindo que embora os métodos originem-se de teorias diferentes, a satisfação apresentou bons resultados com o redesign do jogo. Os resultados também apontaram que os jogadores aumentaram o seu conhecimento com relação ao conteúdo educativo abordado, sugerindo que o processo de redesign foi bem sucedido sob o ponto de vista educacional, tal qual na versão anterior do jogo.
\end{abstract}

Palavras-Chave: Experiência do Jogador; Satisfação; GameFlow; PENS.

\begin{abstract}
Understanding and measuring the player's experience and relating it to use in games for educational purposes has been a challenging field of research. Measuring the quality of the player's experience has been the subject of study by the gaming development community. The satisfaction perceived by the player from his experience has been configured as one of the means to enhance the engagement in games, especially when it comes to purposeful digital games. This article presents the evaluation of the game Caixa de Pandora Mobile after the redesign process of an earlier version. The objective of the study was to first verify if there was a significant difference in player satisfaction from the application of the GameFlow and PENS models, second, to verify the perceived satisfaction of the player in relation to the progress of his knowledge in the content while playing. The statistical results showed that even using models with different approaches, the evaluation of the game did not present a significant difference in the results, suggesting that although the methods are based on different theories, the satisfaction was obtained satisfactorily with the redesign of the game. The results also pointed out that the players increased their knowledge regarding the educational content addressed, suggesting that the redesign process was well succeeded by the educational point of view (as in the previous version of the game).
\end{abstract}

Keywords: Player Experience; Satisfaction; GameFlow; PENS.

Cite as: Felix, Z. C.; Machado, L. dos S.; Silva, J. R. O.; Silva, A. T. M. C. \& Almeida, L. R. de. (2020). The PENS and GameFlow Models to Assess Player Satisfaction: An Analysis with the Game "Caixa de Pandora" Mobile (Os Modelos PENS e GameFlow na Avaliação da Satisfação do Jogador: Uma Análise com o Jogo "Caixa de Pandora” Mobile). Brazilian Journal of Computers in Education (Revista Brasileira de Informática na Educação - RBIE), 28, 664-692. DOI: 10.5753/RBIE.2020.28.0.664 


\section{Introdução}

Nos últimos anos, houve um aumento significativo dos estudos empíricos sobre a eficácia e os benefícios dos jogos digitais na aprendizagem, treinamento, e na capacitação nas mais variadas áreas (Wouters, 2017). Ainda segundo Wouters (2017), na maioria desses estudos esses ambientes de aprendizagem são frequentemente tratados como jogos sérios ou aprendizado baseado em jogos. De acordo com Dörner et al. (2016), um jogo sério é um jogo digital que foi desenvolvido com a intenção de entreter e atingir pelo menos um objetivo adicional, por exemplo, ensinoaprendizagem ou saúde. Neste contexto, Machado (2016) compreende esse "objetivo adicional” como sendo um propósito que deve existir no jogo além do entretenimento, tendo como exemplo, motivar e auxiliar o aprendizado no processo educativo. No entanto, apesar desses estudos terem se concentrado na eficácia e nos benefícios dos jogos sérios e na aprendizagem baseada em jogos, ainda existe um campo promissor para trabalhos que se concentrem em entender e medir a experiência do jogador e relacioná-la ao uso dos jogos com propósitos educacionais.

Deste modo, compreender e medir a experiência do jogador têm sido um aspecto relevante para pesquisadores e desenvolvedores de jogos. Por meio da experiência é possível descrever as qualidades das interações tanto durante quanto após a execução do jogo (Dörner et al., 2016). Mensurar satisfação do jogador pode ser um caminho para potencializar sua experiência, pois a satisfação pode indicar não só os aspectos positivos como também os negativos na estrutura do jogo podendo muitas vezes fornecer indicativos que podem orientar o processo de design e redesign para favorecer a experiência desejada.

O redesign é um processo que gera mudança no desenvolvimento do jogo já produzido (Barbosa \& Silva, 2010). Nele é possível explorar diferentes ideias e soluções para problemas que possam melhorar a experiência do jogador. Entre os motivos que levam ao redesign de um jogo em produção estão: i) a introdução de novas tecnologias, ii) a descoberta de modos de facilitar o uso e iii) as mudanças das necessidades do jogador (Lobach, 2001). As mudanças realizadas a partir do redesign podem afetar a experiência do jogador, pois a estrutura de funcionamento do jogo, a mudança na sequência dos eventos, modificações nos controles audiovisuais, assim como mudança de plataforma, podem ter impacto na experiência do jogador. Para Dörner et al. (2016) a experiência do jogador denota a experiência individual e pessoal de jogar, de modo que um determinado jogo pode motivar e gerar satisfação para uma pessoa e não gerar os mesmos sentimentos para outras. Neste contexto, a motivação humana tem sido estudada em vários trabalhos (Sweetser \& Wyeth, 2005; Rigby \& Ryan, 2007) como um dos fatores que podem contribuir para melhorar a experiência do jogador em jogos digitais. De forma complementar, Dörner et al. (2016) sustentam que a experiência de jogar é algo pessoal, que diz respeito apenas àquela pessoa e, como tal, o uso dos modelos psicológicos podem ser usados para tentar explicar a estrutura da experiência do jogador, bem como alguns dos componentes que podem ter influência na mesma.

Nesse sentido, o objetivo deste trabalho foi avaliar a experiência dos jogadores do jogo com propósito Caixa de Pandora (Almeida et al., 2014; Almeida et al., 2018) após a realização do redesign da sua primeira versão. A avaliação foi realizada em dois momentos distintos: no primeiro, a avaliação foi realizada a partir de dois modelos de avaliação da satisfação: o GameFlow (Sweetser \& Wyeth, 2005), avaliando numa perspectiva do divertimento e prazer de jogar e o Player Experience of Need Satisfaction - PENS (Rigby \& Ryan, 2007), avaliando de um ponto de vista das necessidades básicas psicológicas, do bem-estar e contentamento do jogador. Pretendeu-se, assim, verificar se a satisfação percebida em ambos os modelos apontava para os mesmos resultados. Já no segundo momento, a avaliação da satisfação foi realizada também numa perspectiva do divertimento e prazer de jogar utilizando o instrumento GameFlow (Sweetser \& Wyeth, 2005), mas acrescentando uma nova dimensão: a pedagógica. Neste segundo momento, 
buscou-se verificar se os conhecimentos, comportamentos ou valores dos jogadores são adquiridos ou modificados ao jogarem o Caixa de Pandora Mobile.

Este artigo está organizado da seguinte forma: a Seção 2 apresenta uma breve fundamentação teórica abordando os modelos que foram utilizados na avaliação; a Seção 3 descreve os aspectos metodológicos da pesquisa; a Seção 4 apresenta a análise dos resultados obtidos e discussões. Por fim, a Seção 5 apresenta as considerações finais.

\section{Referencial Teórico}

O presente artigo baseia-se em dois modelos de avaliação da satisfação do jogador: GameFlow e PENS. O GameFlow é um modelo amplamente validado na literatura (Sweetser \& Wyeth, 2005) apresentando resultados consistentes no processo de avaliação de jogos, por conseguinte, vem sendo utilizado com base para vários estudos no desenvolvimento de modelos de avaliação nos mais variados gêneros de jogos digitais, tais como, o EGameFlow (Fu et al., 2009) para jogos educativos. Já o PENS, é fundamentado em uma sólida teoria da motivação humana - Teoria da Autodeterminação-SDT (Ryan \& Deci, 2000).

Embora existam outros modelos de avaliação da satisfação, tais como: Game Experience Questionnaire-GEQ (Poels et al., 2008) e o Core Elements of the Gaming Experience Questionnaire-CEGEQ (Galvillo-Gámez et al., 2010), o uso do GameFlow se justifica por ser um modelo validado e consolidado, aplicável a todos os gêneros e plataformas de jogos. Já com relação ao PENS, o modelo vem se destacando como um importante instrumento no contexto da avaliação da experiência do jogador (Denisova et al., 2016; Dörner et al., 2016), principalmente por abordar aspectos que satisfazem as necessidades psicológicas básicas (competência, autonomia e relacionamento), podendo as mesmas resultar em maiores chances de promover o aprendizado a partir da motivação intrínseca e bem-estar do jogador. A seguir são apresentados alguns trabalhos relacionados e aprofundados os conceitos referentes a esses modelos.

\subsection{Trabalhos Relacionados}

No trabalho de Dias et al. (2016) foi realizada uma avaliação de um jogo educacional de anatomia e fisiologia digestória humana intitulado DigesTower. O jogo foi desenvolvido com foco no ensino de anatomofisiologia para o ensino da enfermagem. O estudo teve como objetivo descrever o design e avaliação do jogo com base no instrumento EGameFlow. A avaliação foi realizada com 13 especialistas. Segundo os resultados obtidos, o jogo foi avaliado positivamente com destaque para as dimensões "Imersão" e "Melhoria do Conhecimento". Ademais, os autores destacam que a partir dos indicadores do EGameFlow foi possível perceber a necessidade de um melhor balanceamento nos níveis de dificuldades dos desafios.

O trabalho de Eckardt e Robra-Bissantz (2019) analisa se existe diferença significativa na experiência de jogo e aprendizado dos alunos, quando se usa o mesmo design de serious game com diferentes conteúdos de aprendizagem. A avaliação foi realizada com base no modelo EGameFlow e contou com a participação de 65 alunos. Os alunos foram divididos em três grupos, e cada grupo utilizou uma versão do jogo com conteúdo distinto. Os resultados não mostram diferenças significativas entre as versões testadas para todas as dimensões medidas do modelo EGameFlow. Para os autores, isso significa que a experiência de jogo e aprendizado é idêntica nas três versões do jogo, logo, torna possível reutilizar o mesmo design do jogo em combinação com outros conteúdos de aprendizado sem afetar negativamente a experiência de jogo e aprendizado do aluno.

Já no trabalho de Ijaz et al. (2020) foi realizado um estudo para avaliar a satisfação do usuário em um jogo de exercícios em ambiente de realidade virtual (RV). A análise foi realizada 
sob duas condições: uma com uma interface estática (IE) e outra com um ambiente de mundo aberto (MA). Os autores avaliaram os dois ambientes com base no PENS para identificar elementos que pudessem contribuir para a satisfação percebida do jogador e, como resultado, sua motivação e prazer. A avaliação foi realizada com 45 participantes com idade entre 18 e 59 anos. Para os autores, o PENS mostrou ser uma abordagem teórica adequada. O estudo revelou diferenças significativas em autonomia, imersão, competência entre as condições de IE e MA. Além disso, dentro de cada condição, as experiências de autonomia e presença eram mais preditivas de satisfação.

Pires et al. (2018) desenvolveram o jogo de propósito educacional "O Livro do Conhecimento" com a finalidade de exercitar a ortografia em língua portuguesa. A partir de teste preliminares, os autores apontaram que o jogo pode potencializar a aprendizagem. O jogo foi avaliado com o modelo EGameFlow e apresentou bons resultados nas seguintes dimensões: concentração, objetivos e feedback. Já as dimensões desafios, habilidades do jogador, controle e imersão, indicaram que o jogo precisava de ajuste nos elementos de design que permeiam tais dimensões.

Observa-se pelos trabalhos citados o uso de técnicas de avaliação da satisfação em jogos com propósito como forma de compreender os elementos dos jogos que precisavam de maior atenção no processo de redesign. No entanto, percebeu-se que existe uma tendência de avaliar os jogos utilizando uma única técnica, como aconteceu em Dias et al. (2016), Eckardt e RobraBissantz (2019) e Ijaz et al. (2020). Contudo, a avaliação a partir de técnicas distintas pode fornecer ao game designer as condições necessárias para que ele possa tomar decisões mais assertivas em relação aos elementos de design do jogo, uma vez que, é possível analisar se os resultados apontam na mesma direção. Ademais, vale ressaltar que além destes trabalhos, existe uma escassez de estudos que apresentam resultados de redesign ou manutenção após o processo de avaliação da satisfação. Esses resultados são importantes para averiguar se as mudanças nos elementos do jogo proporcionam os efeitos desejados, particularmente quando o jogo tem propósito educacional.

Um ponto importante está no acoplamento entre conteúdo pedagógico e os elementos do jogo. No trabalho de Eckardt e Robra-Bissantz (2019), os autores mencionam que apenas com a mudança de conteúdo pedagógico e sem alterações no design, foram encontrar resultados positivos sem afetar a aprendizagem. No entanto, é importante destacar que o conteúdo pedagógico pode estar integrado aos demais elementos da tétrade dos quatro elementos proposta por Schell (2014) (mecânica, narrativa, estética e tecnologia). Neste caso, uma mudança do conteúdo pedagógico poderia afetar o equilíbrio de tais elementos e, consequentemente comprometer a satisfação e aprendizado do jogador.

De modo geral, os trabalhos mencionados sugerem que os elementos do jogo podem sofrer mudanças, e que tais mudanças afetam a satisfação. Considerando-se os jogos com propósito educacional, estando ou não o conteúdo educacional atrelado aos demais elementos da tétrade de Schell, alterações nestes elementos podem impactar na satisfação do jogo como um todo, o que comprometeria a sua aceitação e impacto no contexto de sua aplicação educacional.

\subsection{GameFlow}

O GameFlow foi um modelo proposto para avaliar jogos sob a premissa da diversão, do contentamento e do prazer em jogar um jogo (Sweetser \& Wyeth, 2005). O modelo GameFlow é derivado dos estudos de Csikszentmihalyi (1999) sobre a teoria do Flow e da síntese da aplicação deste conceito na área de jogos digitais existentes na literatura (Sweetser \& Wyeth, 2005). A teoria do Flow nasceu há mais de trinta anos como resultado dos estudos do psicólogo húngaro Mihaly Csikszentmihalyi (1999), sobre o que faz com que algumas pessoas possam ter experiências tão gratificantes e agradáveis que as mesmas fariam sem a expectativa de ganho ou recompensa 
externa, apenas para se sentirem bem (O'Brien \& Tons, 2008; Whitton, 2010), essa experiência foi chamada de Flow pelo seu idealizador. Flow apresenta 8 elementos característicos, sendo compreendidos da seguinte forma:

- Equilíbrio entre as habilidades e os desafios: há um equilíbrio entre o desafio com o qual a pessoa está envolvida e sua capacidade de resolvê-lo de forma adequada;

- Fusão entre ação e consciência: As ações realizadas durante a tarefa parecem ser realizadas de forma automática, quase sem a pessoa perceber suas ações;

- Objetivos claros: clareza sobre o objetivo a ser atingido, o estabelecimento de clareza nos objetivos facilita a concentração, e permanência do foco na tarefa;

- Feedback imediato: resposta imediata sobre o desempenho ou progresso na tarefa;

- Concentração na tarefa: a atenção está totalmente na tarefa;

- Um senso de controle: sem a sensação de preocupação em perder o controle;

- Perda de autoconsciência: não há espaço na consciência para pensamentos ou sentimentos que não estejam relacionados com a tarefa.

- Transformação do tempo: sentimento de desorientação temporal ou perda da noção da passagem do tempo.

A teoria do Flow propõe a noção de que certos elementos podem aumentar a satisfação com uma experiência, de modo que, quanto mais presentes estão esses elementos, mais agradável, atraente e prazerosa será a mesma (Carvalho \& Ishitani, 2013). No contexto dos jogos digitais, Sweetser e Wyeth (2005) propuseram que no modelo GameFlow a "experiência ótima” ou a "satisfação do jogador" pode ser obtida a partir de elementos mapeados da teoria de Flow. Esses elementos consistem em concentração, desafio, habilidades, controle, objetivos claros, feedback, imersão e interação social, sendo que, cada um desses elementos possui um conjunto de critérios. Ainda de acordo com estas pesquisadoras, para que haja o prazer e diversão em jogar é necessário que cada elemento esteja presente e tenha interação com um ou mais dos outros elementos. A Tabela 1 apresenta um resumo descritivo dos elementos do modelo GameFlow (Sweetser \& Wyeth, 2005).

Tabela 1: Elementos do GameFlow - (Sweetser \& Wyth).

\begin{tabular}{ll}
\hline Elemento & Descrição \\
\hline Concentração & Os jogos exigem concentração e o jogador deve se concentrar no jogo. \\
\hline Desafio & Os jogos devem fornecer desafios que correspondam as habilidades do jogador. \\
\hline Habilidades do jogador & Os jogos devem desenvolver suas habilidades do jogador enquanto joga. \\
\hline Controle & Os jogos devem fornecer aos jogadores a sensação de controle sobre suas ações. \\
\hline Objetivos claros & Os objetivos do jogo devem ser compreendidos de forma clara e objetiva. \\
\hline Feedback & Os jogadores devem receber feedback apropriado e no tempo apropriado. \\
\hline Imersão & Os jogos devem fornecer aos jogadores a experiência de profundo envolvimento com \\
\hline Interação Social & Devemo, mas sem esforço no jogo. \\
\hline
\end{tabular}

Para avaliar o jogo a partir dos elementos do GameFlow é necessário pontuar o conjunto de critérios de cada elemento. Os critérios recebem valores entre zero (0) e 5 (cinco). Conforme Sweetser e Wyeth (2005), o valor zero indica que esse critério não se aplica ao contexto do jogo, enquanto os valores de 1 a 5 indicam respectivamente "não tem”, “abaixo da média” (ruim), "na média”, “acima da média” e "atendido totalmente” (Sweetser \& Wyeth, 2005). Apesar do modelo ser utilizado principalmente para avaliação de jogos, nada impede que os seus elementos sejam utilizados como heurísticas para o projeto de design de jogo, que segundo Tsuda et al. (2014) e Sweetser et al. (2017) pode ser de grande utilidade para o game designer entender quais os aspectos positivos e negativos do jogo sob a perspectiva do jogador. Nesta direção, Jegers (2007) 
reforça a importância da utilização dos elementos do modelo GameFlow, pois segundo o autor, a diversão e o prazer dos usuários em jogar é talvez a questão mais importante no design de jogos de sucesso. A satisfação avaliada pelos critérios estabelecidos pelo GameFlow poderá fornecer um indicativo de quais aspectos poderão ser otimizados para motivar e manter o jogador interessado no jogo.

Em jogos com propósitos educacionais a satisfação percebida do jogador deve mensurar não apenas o divertimento, mas o conhecimento adquirido a partir da experiência do jogador. Com isso, se faz necessário adotar instrumentos de avaliação que além dos aspectos da diversão também possa avaliar o conhecimento obtido pelo jogador ao longo do jogo. Nesta direção, Fu et al. (2009) desenvolveram um instrumento chamado EGameFlow, esse instrumento é baseado no GameFlow de Sweetser e Wyeth (2005) e fornece uma escala de satisfação do jogador com o jogo contemplando o propósito educacional. Da mesma maneira que ocorre no GameFlow, o EGameFlow pode fornecer indicativos ao game designer de quais aspectos do jogo podem ser potencializados.

O EGameFlow apresenta uma escala de oito dimensões, sendo elas: Concentração, Clareza dos Objetivos, Feedback, Desafios, Autonomia, Imersão, Interação Social e Melhoria do Conhecimento. As dimensões apresentam vários itens, que são analisados para determinar a nota de cada dimensão (Tsuda et al., 2014). Para uma melhor compreensão das dimensões estabelecidas no método, a Tabela 2 apresenta um descritivo de cada dimensão.

Tabela 2: Dimensões do EGameFlow (Fu et al., 2009)

\begin{tabular}{ll}
\hline Elemento & Descrição \\
\hline Concentração & $\begin{array}{l}\text { Essa dimensão é composta por } 8 \text { itens e analisa se o jogo fornece atividades que } \\
\text { incentivam a concentração do jogador. }\end{array}$ \\
\hline Clareza dos Objetivos & $\begin{array}{l}\text { Avalia se o jogo apresenta claramente os seus objetivos (primários e secundários) no } \\
\text { início do jogo. Essa dimensão é composta por } 5 \text { itens. }\end{array}$ \\
\hline Feedback & $\begin{array}{l}\text { Esta dimensão contém } 6 \text { itens e avalia se o jogo fornece informações referentes ao } \\
\text { progresso do jogador, sobre as suas ações, bem como o seu sucesso ou fracasso. }\end{array}$ \\
\hline Desafios & $\begin{array}{l}\text { Avalia se os desafios do jogo estão em equilíbrio com o nível de habilidades do } \\
\text { jogador. Essa dimensão é composta por } 10 \text { itens. }\end{array}$ \\
\hline Autonomia & $\begin{array}{l}\text { Esta dimensão contém } 9 \text { itens, e analisa a iniciativa do jogador, bem como o controle } \\
\text { total sobre suas escolhas no jogo. }\end{array}$ \\
\hline Imersão & $\begin{array}{l}\text { Verifica o estado de imersão do jogador no jogo, neste caso, o quanto o jogo } \\
\text { potencializa a imersão do jogador. Essa dimensão é composta por } 7 \text { itens. }\end{array}$ \\
\hline Interação Social & $\begin{array}{l}\text { Esta dimensão analisa se as tarefas do jogo oferecem oportunidades para os jogadores } \\
\text { interagirem socialmente. A dimensão é formada por } 6 \text { itens. }\end{array}$ \\
\hline Melhoria do Conhecimento & $\begin{array}{l}\text { Responsável por verificar se o jogo aumenta o nível de conhecimento e habilidades } \\
\text { do jogador, ao mesmo tempo que cumpre com o conteúdo educacional estabelecido. } \\
\text { A dimensão é formada por } 5 \text { itens. }\end{array}$ \\
\hline
\end{tabular}

Para realizar a avaliação de um jogo a partir do instrumento EGameFlow, é necessário atribuir um valor para cada um dos itens das dimensões apresentados em escalas do tipo Likert, com 1 e 7 representando respectivamente o menor e o maior grau em que os respondentes concordam com os itens. Para obter a nota final de uma determinada dimensão do jogo avaliado, se faz necessário calcular a média das notas dos itens daquela dimensão. No caso de uma dimensão seja avaliada com média 7,00 (sete), ela atenderá satisfatoriamente aos critérios estabelecidos naquela dimensão.

Segundo Fu et al. (2009), EGameFlow é um método de avaliação fácil e econômica para avaliar principalmente a satisfação dos jogadores em jogos com propósito educacional. Para os autores, o método pode ser usado como heurísticas para obter uma visão melhor da opinião dos 
jogadores, possibilitando assim, uma maior compreensão dos aspectos que precisam ser melhorados para potencializar o prazer e a satisfação do jogador jogar o jogo. Da mesma forma que acontece com o uso do GameFlow, o resultado da avaliação do EGameFlow também pode ser usado pelo game designer para refinar o produto final em um processo de redesign.

\subsection{Teoria da Autodeterminação em Jogos Digitais}

Os estudos no campo da experiência do usuário em jogos digitais apontam para o fato de que a experiência do jogador é uma experiência positiva quando contempla a presença de motivação intrínseca (Dorner et. al, 2016). É comum perceber que quando existe motivação intrínseca na prática de uma tarefa, existe uma tendência dessa tarefa ser mais satisfatória para o indivíduo (Carvalho \& Ishitani, 2013). A motivação intrínseca diz respeito à satisfação pessoal e espontaneidade na realização de uma tarefa no qual não se espera recompensa externa (Ryan \& Deci, 2000). De acordo com Dörnet et al. (2016) existem vários estudos na literatura que tentam explicar em que momento surge a motivação intrínseca na prática de uma tarefa. Dentre esses estudos destaca-se a teoria da autodeterminação (SDT) proposta por Ryan e Deci (2000).

A Teoria da Autodeterminação (SDT), é uma teoria psicológica estabelecida da motivação humana e da personalidade (Ryan \& Deci, 2000). A SDT aborda principalmente fatores que permitem a motivação intrínseca. Segundo estes pesquisadores, os indivíduos são motivados a buscar atividades que satisfaçam as suas necessidades psicológicas básicas que são essenciais para o contínuo crescimento psicológico e bem-estar. A SDT é apresentada como um modelo que investiga as necessidades psicológicas básicas de autonomia, competência e relacionamento, que são a base para a automotivação e integração de personalidade (Ryan \& Deci, 2000). A teoria argumenta que a partir da satisfação de suas necessidades básicas, os indivíduos apresentam maiores chances de evoluir no seu ambiente, seja ele, virtual ou real. Assim, os pesquisadores descrevem três necessidades básicas da seguinte forma:

- Competência: refere-se a eficácia das ações da pessoa no ambiente atual e ter um efeito sobre esse ambiente de forma que alcance os resultados esperados (Ryan \& Deci, 2000). Eventos que conduzem a sentimentos de competência durante a realização de uma tarefa podem potencializar a motivação intrínseca. Para (Ryan \& Deci, 2000), eventos tais como desafios em um nível ótimo e feedback positivos facilitam a motivação intrínseca.

- Autonomia: a autonomia diz respeito à necessidade interna de ser responsável por suas próprias escolhas, provê um senso de independência nas escolhas (Ryan \& Deci, 2000). A autonomia refere-se aos interesses, preferências e vontades que podem guiar as pessoas na tomada de decisões sobre participar ou não de uma tarefa (Almeida et al., 2014; Ryan \& Deci, 2000).

- Relacionamento: refere-se ao envolvimento social e a relação com outras pessoas, grupos de pessoas ou comunidades. O senso de envolvimento social fortalece os vínculos afetivos através da interação entre as pessoas, de modo que, quando essa interação ocorre de forma significativa e afetiva, ela pode promover motivação (Almeida et al., 2014; Ryan \& Deci, 2000).

De modo geral, a SDT aponta no sentido de que a motivação intrínseca humana é substancialmente influenciada pela necessidade humana de autonomia, competência e relacionamento social (Dorner et. al., 2016). No âmbito dos jogos digitais as recompensas intrínsecas tendem a ser o principal fator motivador, fazendo da SDT uma teoria particularmente útil para explicar a satisfação do jogador (Tamborini, 2010). De forma complementar, (Ryan et al., 2006) argumentam que os jogos apresentam motivação na medida que os jogadores vivenciam autonomia, competência e relacionamento (vínculo social) durante a execução do jogo.

Para aplicar a SDT no contexto dos jogos digitais, Rigby e Ryan (2007) estenderam a SDT para formalizar o modelo Player Experience of Need Satisfaction (PENS). Segundo os autores, 
um dos objetivos do modelo é medir elementos da experiência do jogador que podem ser mais satisfatórios na experiência de jogar o jogo. De acordo com os pesquisadores, ao longo dos últimos 30 anos diversos estudos testaram modelos motivacionais tanto na área de trabalho quanto na de lazer. Esses estudos apontam que a motivação em praticar alguma tarefa pode ser explicada por três necessidades psicológicas intrínsecas: as de competência, autonomia e relacionamento. Para Rigby e Ryan (2007), essas necessidades compreendem a essência do modelo PENS, sendo que, cada uma dessas necessidades pode se comportar de maneira diferente dentro do contexto de um jogo, principalmente em relação a um ou mais dos três aspectos do jogo (mecânica, jogabilidade e narrativa).

No PENS, a escala de satisfação do jogador é baseada na satisfação das necessidades básicas psicológicas (Competência, Autonomia e Relacionamento), além da "Presença” e de "Controles Intuitivos” (Ryan et al., 2006). A escala é organizada em cinco dimensões e podem ser compreendidas da seguinte forma (Rigby \& Ryan, 2007):

- Competência no jogo: Esta dimensão diz respeito a um equilíbrio adequado entre os desafios do jogo e o nível de competência dos jogadores. Expressa a satisfação do jogador em conquistar os desafios e de se sentir capaz perante o jogo. Por exemplo, caso os jogadores não se sintam capazes de dominar aspectos relacionados com a mecânica do jogo, tais como, controles e interface gráfica, eles geralmente tendem a ter uma experiência frustrante e consequentemente essa experiência poderá atuar como uma barreira no engajamento e na satisfação com o jogo (Rigby \& Ryan, 2007).

- Autonomia no jogo: Esta dimensão expressa a experiência dos jogadores em se sentirem livres para tomar decisões e escolhas no jogo. Neste sentido, Birk e Mandryk (2013) acreditam que os jogos que oferecem diversas opções dentro do jogo dão aos jogadores a oportunidade de experimentar autonomia através da tomada de decisão. Quando as atividades são feitas por interesse ou valor pessoal, a autonomia percebida é alta (Ryan \& Deci, 2000).

- Relacionamento no jogo: Esta dimensão diz respeito ao quanto os jogadores estão se sentindo conectados a outros jogadores no jogo. Para Birk e Mandryko (2013), os jogos sociais como FarmVille e jogos de modalidade MMORPG (Massive Multiplayer Online Role Playing Game, por exemplo, World of Warcraft) fazem um largo uso deste conceito. Nesse contexto, Rigby e Ryan (2007) reforçam ainda que, jogos que apresentam características multiplayer favorecem a experiências de relacionamentos mais reais nos seus mais variados graus e podem contribuir significativamente para a motivação e a satisfação do jogador.

- Presença: Esta dimensão diz respeito ao quanto o jogador se sente presente e imerso no mundo do jogo. A presença é subdividida em três subdimensões, isto é, presença física, emocional e narrativa. De acordo com Ryan e Deci (2000) a presença física, fornece ao jogador a sensação de estar realmente no mundo virtual do jogo, presença emocional permite ao jogador a sensação que os eventos do jogo têm um peso emocional real; a presença narrativa representa um investimento pessoal e engajamento com a história do jogo.

- Controles intuitivos: Esta dimensão diz respeito ao grau em que os controles do jogo são intuitivos, ou seja, se eles fazem sentido no jogo, se são facilmente dominados e não interferem na sensação de estar no jogo (senso de presença) (Ryan et al., 2006; Rigby \& Ryan, 2007). Para Ryan et al. (2006) os controles intuitivos podem potencializar o senso de competência do jogador, pois os mesmos podem contribuir para a motivação do jogo em função de estarem associados a uma maior sensação de liberdade e controle. 
Para avaliar a satisfação do jogador no jogo, o modelo PENS fornece um instrumento de avaliação com 21 itens distribuídos nas cinco dimensões. Cada item usa uma escala Likert de sete pontos variando de 1 a 7 (de “discordo totalmente” para “concordo totalmente”).

Além da contribuição fornecida pelo instrumento de avaliação a partir do questionário, o modelo PENS traz consigo outras contribuições conceituais que podem servir tanto no planejamento quanto no desenvolvimento de jogos (Rigby \& Ryan, 2007). Dentre elas, pode-se verificar:

1. Pode servir como heurísticas para inspirar os desenvolvedores nos projetos de desenvolvimento de jogos;

2. Pode fornecer uma compreensão das necessidades motivacionais dos jogadores e consequentemente auxiliar nas escolhas específicas para o design do jogo;

3. Fornece uma metodologia que mensura a satisfação dos jogadores independentemente da abordagem tecnológica, haja vista a constante evolução dessas tecnologias (consoles, plataformas, gráficos).

4. Fornece uma nova visão para avaliar a experiência do jogador, não apenas pelo lado da diversão e do lazer, mas em termos da sua satisfação genuína e do seu bem-estar.

Em síntese, o modelo PENS traz consigo a aplicação de uma teoria sólida que aborda a motivação do jogador. Essa teoria contribui fortemente no sentido de fornecer uma maior compreensão por parte dos desenvolvedores sobre o que fundamentalmente traz satisfação aos jogadores. Além disso, fornece uma metodologia para mensurar essa satisfação (Ryan et al., 2006; Rigby \& Ryan, 2007).

\section{Aspectos Metodológicos}

O presente trabalho apresentou como finalidade a avaliação da experiência do jogador na utilização do jogo Caixa de Pandora na sua versão móvel para plataforma Android. A avaliação do Caixa de Pandora Mobile teve como foco principal avaliar a satisfação do jogador utilizando dois instrumentos distintos e amplamente conhecidos na literatura. A utilização dos instrumentos teve como propósito comparar os resultados a fim de perceber tanto os aspectos positivos quanto os negativos que podem influenciar na satisfação e no engajamento dos jogadores com a aplicação. Os resultados obtidos serão utilizados como heurísticas para melhorar o jogo no que se refere ao engajamento e à satisfação dos jogadores em futuras versões. A avaliação do jogo foi realizada em momentos e públicos-alvo distintos.

A primeira avaliação da aplicação foi realizada por 30 estudantes de duas turmas de graduação de um curso de Enfermagem de uma instituição de ensino particular, e por estudantes de um curso de pós-graduação de uma instituição de ensino público. Os participantes do teste utilizaram o jogo e depois foram divididos em dois grupos com o objetivo de responderem instrumentos distintos, sendo: a) Grupo G1 e, b) Grupo G2. Os jogadores do grupo G1 responderam o instrumento do GameFlow, enquanto os jogadores do grupo G2 responderam o instrumento do PENS. Os participantes foram selecionados aleatoriamente para cada grupo, a fim de ter um equilíbrio entre os participantes que responderam qualquer um dos instrumentos.

Já na segunda avaliação, os testes foram realizados por 60 estudantes com idade entre 14 e 18 anos de quatro turmas de uma escola estadual de ensino médio integrado à educação profissional. Os estudantes estão matriculados nos cursos de Hospedagem, Eventos, Manutenção e Suporte em Informática. Todos os participantes do teste foram agrupados em um único grupo, pois, nessa avaliação seria utilizado apenas um instrumento para medir a satisfação percebida dos jogadores e evolução pedagógica. Todos os estudantes utilizaram o mesmo instrumento de satisfação do GameFlow. Os participantes foram inicialmente orientados a instalar o jogo em seus 
dispositivos móveis antes dos testes presenciais realizados na escola. A seção 3.3 apresenta um maior detalhamento dos procedimentos de avaliação. A seguir será apresentado uma breve descrição do Jogo Caixa de Pandora e os instrumentos utilizados para mensurar a satisfação dos jogadores, bem como, os procedimentos adotados para cada processo de avaliação.

\subsection{Caixa de Pandora Mobile}

O Caixa de Pandora Mobile é uma extensão do trabalho de Almeida et al. (2014). Neste trabalho, os autores apresentam o serious game (SG) intitulado "Caixa de Pandora”. O principal objetivo do jogo é capacitar profissionais de saúde em relação à violência doméstica contra a mulher (VDCM), no sentido de mobilizar novos saberes e orientar mudança de práticas, possibilitando uma atenção mais integral e resolutiva à mulher em situação de violência doméstica. Ademais, este SG foi desenvolvido para disseminar os conceitos relacionados aos temas sobre VDCM, bem como promover uma maior reflexão sobre a temática.

O jogo baseia-se na apresentação de cenas com passagens da vida da personagem, seguidas de perguntas ao jogador. Deste modo, ele traz como desafio ao jogador entrar na "Caixa de Pandora” para desvendar os mistérios e sentimentos que permeiam a problemática da violência contra a mulher. Com isso, o jogador busca ajudar a personagem Marta, que sofre por constantes situações de opressão e violência, cometidas pelo companheiro, e que recorre ao serviço de saúde. A estória do jogo se desenrola em três em 3 níveis de acordo com a fase de vida da personagem: infância, idade adulta com companheiro e filhos, e idade adulta como vítima de violência pelo companheiro. Cada uma destes 3 níveis aborda três grandes categorias da temática da VDCM: (1) Gênero, (2) Direitos Humanos e (3) Saúde (Almeida et al., 2014). A infância de Marta aborda as categorias (1) ou (2) de maneira introdutória; a idade adulta com companheiro e filhos aborda as categorias (2) e (3); e a idade adulta como vítima de violência pelo companheiro aborda as 3 categorias de maneira integrada, com maior foco na categoria (3).

A Figura 1(a) apresenta uma das telas que compõem uma cena da categoria (1). Já a Figura 1(b) traz uma tela do jogo com a apresentação da pergunta, alternativas e reflexão da resposta mais adequada. O jogador deve agir diante dos mistérios e segredos que o jogo apresenta, visando facilitar a aprendizagem sobre a violência contra a mulher.

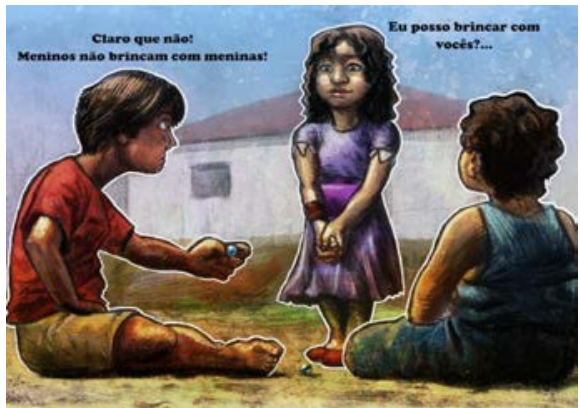

(a)

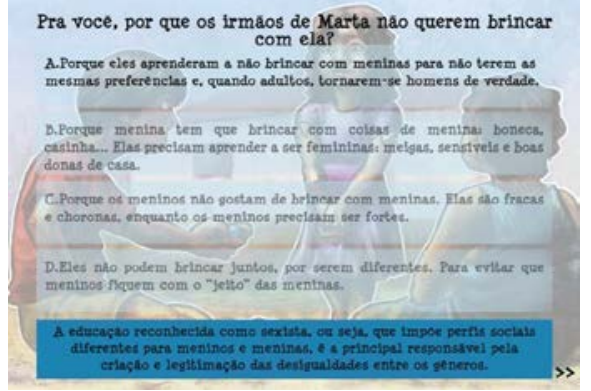

(b)

Figura 1: Interfaces do Caixa de Pandora

Recentemente, foi realizado o redesign do jogo, adequando-o para execução em plataformas móveis que utilizam o sistema operacional Android e ampliando o seu público-alvo para indivíduos acima de 13 anos. A motivação de migrar o jogo original para uma plataforma móvel se deu por entender que: primeiro, ainda existe uma carência muito grande em ferramentas que abordem essa temática; segundo, pelo fato de poder ampliar o acesso e aquisição do conhecimento, tanto dos profissionais de saúde, quanto dos estudantes e da sociedade geral; e terceiro, por disponibilizar a aplicação por meio de tecnologia móvel cujo acesso pode ocorrer em qualquer lugar e em qualquer tempo. Na Figura 2(a) e 2(c) ilustram algumas interfaces que são 
trabalhadas nos passatempos (desafios) do jogo. Já a Figura 2(b) apresenta cenas que abordam um dos desafios do jogo, neste caso específico, o desafio "Coisa de Mulher”. Sendo assim, o redesign ocorreu com: a redefinição da linguagem dos diálogos, com menos termos técnicos e não voltada ao profissional de saúde; a forma de apresentação das respostas, que passou a ter ordenação aleatória; e atualização da dinâmica de interação por meio de toque.

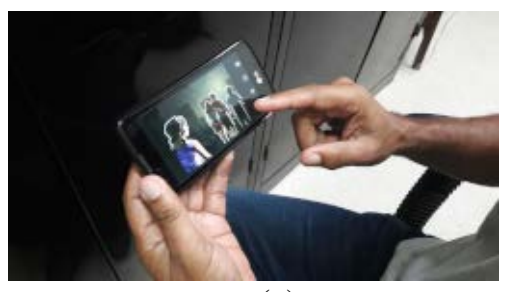

(a)

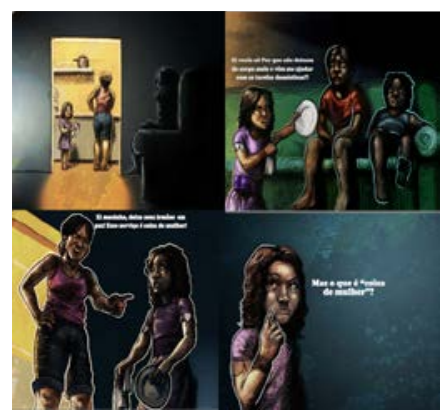

(b)

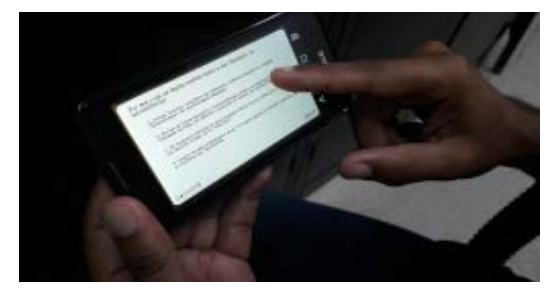

(c)

Figura 2: Interfaces do Caixa de Pandora Mobile

\subsection{Questionários}

Para a primeira avaliação foram utilizados os questionários GameFlow e PENS. O questionário GameFlow utilizado nesse estudo foi adaptado de Sweetser e Wyeth (2005) que consiste dos seguintes fatores: concentração, desafio, habilidades, controle, objetivos claros, feedback, imersão e interação social. Para a aplicação deste questionário foi removido o fator "interação social” uma vez que o jogo Caixa de Pandora não contempla a interação social entre os jogadores. Para o preenchimento de cada item do questionário foi utilizada uma escala Likert de cinco pontos variando de 1 a 5 (de “discordo totalmente” para “concordo totalmente”). O Quadro 1 mostra o questionário do modelo GameFlow utilizado na avaliação.

Já o questionário PENS utilizado foi adaptado de Inchamnan (2016). O questionário consiste dos seguintes fatores: competência, autonomia, relacionamento (vínculo social), imersão/presença e controles intuitivos. Para a aplicação do questionário PENS, foi retirado a fator "relacionamento", pois, o jogo Caixa de Pandora não contempla relacionamento (vínculo social) entre os jogadores. Para o preenchimento de cada item do questionário foi utilizada uma escala Likert de sete pontos variando de 1 a 7 (de “discordo totalmente" para "concordo totalmente”). O Quadro 2 apresenta o questionário PENS utilizado para na avaliação.

Para a segunda avaliação, foi utilizado o questionário GameFlow (Sweetser \& Wyeth, 2005) acrescido da dimensão "Melhora de Conhecimento" do EGameFlow (Fu et al., 2009). Essa escolha teve como objetivo manter as dimensões para analisar comparativamente o nível de satisfação dos jogadores em relação aos resultados da primeira avaliação, bem como, verificar se o jogo aumenta o nível de conhecimento e habilidades do jogador enquanto joga a partir da dimensão "Melhora de Conhecimento". O questionário consiste dos seguintes fatores: concentração, desafio, habilidades, controle, objetivos claros, feedback, imersão e interação social e Melhora de Conhecimento. Para a aplicação do questionário foi necessário também remover o fator “interação social” uma vez que o jogo Caixa de Pandora não contempla a interação social entre os jogadores. Para o preenchimento de cada item do questionário foi utilizada uma escala Likert de cinco pontos variando de 1 a 5 (de "discordo totalmente” para "concordo totalmente”). O Quadro 3 apresenta o questionário do modelo GameFlow adaptado utilizado na avaliação.

Quanto à estrutura, os questionários GameFlow e PENS, foram estruturados da seguinte forma: a) Características sociodemográficas (idade, sexo, formação acadêmica, atuação profissional) e experiência quanto ao uso de dispositivos tecnológicos e jogos digitais; b) Dados referente aos fatores de satisfação do jogador; e c)Sugestões e observações para a melhoria do 
jogo. Observa-se que, apesar de ambos os questionários utilizarem a escala de Likert, optou-se por não alterar as escalas originais dos questionários e realizar a compatibilização dos resultados posteriormente.

Quadro 1: Questionário GameFlow

\begin{tabular}{l} 
Avaliação do GameFlow \\
\hline Concentração \\
C1. Fiquei bastante atento ao jogo em função dos estímulos que foram fornecidos pelos desafios (passatempos) \\
enquanto jogava. \\
C2. Houve algo interessante no início do jogo, pois a minha atenção foi capturada rapidamente me mantendo \\
concentrado no jogo enquanto jogava. \\
C3. Não me senti sobrecarregado pelos desafios (passatempos) do jogo. \\
C4. Percebi que o volume de conhecimento a ser observado era grande, mas adequado as minhas habilidades \\
(cognição, percepção e memória).
\end{tabular}

\section{Desafios}

D1. Me senti capaz para concluir os desafios (passatempos) que foram propostos.

D2. Enquanto eu jogava percebi diferentes níveis de desafios no jogo.

D3. Senti que os novos desafios são apresentados em um ritmo adequado para o aprendizado.

\section{Habilidades do Jogador}

H1. Foi fácil entender o jogo e começar a jogar. Não precisei ler as instruções ou qualquer material auxiliar.

H2. Para mim, aprender o jogo não foi chato ou monótono, mas sim divertido.

H3. Verifiquei que existia um help (manual de instruções) no próprio ambiente do jogo.

H4. Percebi que o jogo também permitia o aprendizado a partir de tutoriais jogáveis.

H5. Percebi que o meu conhecimento (habilidades) sobre a temática do jogo aumentava a partir do meu progresso ao longo do jogo.

H6. Fui recompensado pelo meu esforço e pelo conhecimento obtido enquanto jogava.

H7. Não encontrei dificuldades em aprender a jogar o jogo, pois a interação com as telas e a compressão dos desafios são de fácil entendimento.

\section{Controle}

C1. Sempre tive controle sobre as minhas interações no jogo.

C2. Me senti no controle na manipulação (ou utilização) das telas, botões, menus e demais elementos de interação de forma apropriada.

C3. Tive controle sobre o andamento do jogo, de modo que consegui iniciar, parar, rever os desafios, e sair do jogo de forma apropriada, sem causar nenhum transtorno enquanto jogava.

C4. Vi que o controle sobre o jogo e minhas ações são importantes e que refletem (pode modificar) no mundo jogo.

C5. Tive a sensação de estar no controle das minhas ações e estratégias, e me senti livre para utilizá-la da melhor maneira possível.

\section{Objetivos}

O1. Percebi o objetivo principal do jogo logo no início do jogo.

O2. Ao longo do jogo percebi que havia alguns objetivos intermediários que foram apresentados (ou propostos) no decorrer dos desafios.

\section{Feedback}

F1. Tive informações sobre o meu progresso no jogo enquanto jogava.

F2. Tive respostas imediatas sobre as minhas ações no jogo enquanto jogava.

F3. O meu status no jogo e pontuação estavam sempre visíveis.

\section{Imersão}

I1. Fiquei envolvido emocionalmente no jogo.

I2. Perdi a consciência e não vi o tempo passar enquanto jogava.

I3. Me senti profundamente envolvido com o jogo, a ponto de perder a consciência do que estava acontecendo ao meu redor enquanto jogava.

Interação social - (Não se aplica) 
Quadro 2: Questionário PENS

\begin{tabular}{|l|}
\hline \multicolumn{1}{|c|}{ The Player Experience of Need Satisfaction - PENS } \\
\hline PENS: Competência \\
C1. Eu me sinto competente(hábil) para enfrentar os desafios do jogo. \\
C2. Eu me sinto muito capaz e eficiente quando estou jogando. \\
C3. Minhas habilidades de jogar o jogo estão de acordo com os desafios (passatempos) que foram propostos. \\
\hline PENS: Autonomia \\
A1. O jogo me oferece opções e escolhas interessantes que me faz sentir vontade de realizar os desafios. \\
A2. O jogo permite que eu faça coisas interessantes (sentimento de novas oportunidades durante no jogo). \\
A3. Senti bastante liberdade no jogo para tomar minhas decisões. \\
\hline PENS: Presença / Imersão \\
P1. Ao jogar o jogo, sinto-me transportado para outro tempo e lugar. \\
P2. Explorar o mundo do jogo faz-me sentir como se estivesse viajando para um novo lugar. \\
P3. Ao explorar o mundo do jogo faz-me sentir como se estivesse realmente lá. \\
P4. Eu não sou influenciado/afetado emocionalmente pelos eventos no jogo. \\
P5. O jogo me envolveu emocionalmente. \\
P6. Experimento sentimentos tão profundos no jogo quanto na vida real. \\
P7. Ao jogar o jogo eu sinto como se eu fizesse parte da história. \\
P8. Quando realizo algo no jogo, sinto-me orgulhoso. \\
P9. Eu tive reações a eventos e personagens no jogo como se fossem reais. \\
\hline PENS: Controles intuitivos \\
I1. Aprender os controles (clique/toque em telas, menus, atalhos, botões, caixas) do jogo foi fácil. \\
I2. Os controles do jogo são intuitivos. \\
I3. Quando eu queria fazer algo no jogo, era fácil lembrar o controle correspondente. \\
\hline PENS: Relacionamento - (Não se aplica) \\
\hline
\end{tabular}

Quadro 3: Questionário GameFlow com a dimensão Melhoria do Conhecimento (Sweetser e Wyeth, 2005; Fu et al., 2009)

\begin{tabular}{l} 
Avaliação do GameFlow \\
\hline Concentração \\
C1. Fiquei bastante atento ao jogo em função dos estímulos (estória, imagens, sons etc) que foram fornecidos \\
pelos passatempos enquanto jogava. \\
C2. Houve algo interessante no início do jogo, pois a minha atenção foi capturada rapidamente me mantendo \\
concentrado no jogo enquanto jogava. \\
C3. Não me senti sobrecarregado pelos passatempos do jogo. \\
C4. Percebi que a quantidade de informações apresentadas era grande, mas adequadas às minhas habilidades.
\end{tabular}

\section{Desafios}

D1. Me senti capaz de concluir os passatempos que foram propostos.

D2. Enquanto eu jogava percebi diferentes níveis de passatempos no jogo.

D3. Senti que os novos passatempos eram apresentados em um ritmo adequado para o aprendizado.

\section{Habilidades do Jogador}

H1. Foi fácil entender o jogo e começar a jogar. Não precisei ler instruções ou qualquer material auxiliar.

H2. Para mim, aprender o jogo não foi chato ou monótono, mas sim divertido.

H3. Verifiquei que existia um help (manual de instruções, tutoriais, etc) no próprio ambiente do jogo.

H4. Percebi que o jogo também permitia o aprendizado a partir de tutoriais jogáveis.

H5. Percebi que o meu conhecimento (habilidades) sobre a temática do jogo aumentava a partir do meu progresso ao longo do jogo.

H6. Recebi recompensas pelo meu esforço e pelo conhecimento obtido enquanto jogava.

H7. Não encontrei dificuldades em aprender a jogar o jogo, pois a interação com as telas e a compressão dos passatempos são de fácil entendimento. 


\section{Controle}

C1. Sempre tive controle sobre as minhas ações no jogo.

C2. Me senti no controle na manipulação das telas, botões, menus e demais elementos do jogo.

C3. Tive controle sobre o andamento do jogo, de modo que consegui iniciar, parar, rever os passatempos, e sair do jogo de forma apropriada, sem causar nenhum erro enquanto jogava.

C4. Vi que o meu controle do jogo e minhas ações são importantes e que podem modificar o jogo.

C5. Tive a sensação de estar no controle das minhas ações e estratégias, e me senti livre para utilizá-la da melhor maneira possível.

\section{Objetivos}

O1. Percebi o objetivo principal do jogo logo no início.

O2. Ao longo do jogo percebi que havia alguns objetivos intermediários que foram apresentados (ou propostos) no decorrer dos passatempos.

\section{Feedback}

F1. Tive informações sobre o meu progresso no jogo enquanto jogava.

F2. Tive respostas imediatas sobre as minhas ações no jogo enquanto jogava.

F3. O meu status (estado) no jogo e pontuação estavam sempre visíveis.

\section{Imersão}

I1. Fiquei envolvido emocionalmente no jogo.

I2. Perdi a noção de tempo e não vi o tempo passar enquanto jogava.

I3. Me senti profundamente envolvido com o jogo, a ponto de perder a noção do que estava acontecendo ao meu redor enquanto jogava.

Interação social - (Não se aplica)

\section{Melhora de Conhecimento}

K1. Senti que o jogo ampliou meu conhecimento sobre o tema violência doméstica contra a mulher.

K2. Entendi quais foram as ideias básicas do conhecimento trabalhado (discutido/ensinado) no jogo.

K3. Tentei aplicar meus conhecimentos no jogo.

K4. O jogo me motivou a usar o conhecimento adquirido no dia a dia.

K5. O jogo me deu vontade de conhecer melhor os problemas relacionados com o tema.

\subsection{Procedimento de avaliação}

Após o processo de redesign, a avaliação do jogo foi realizada em dois momentos distintos. No primeiro, o objetivo foi verificar se existia diferença significativa na satisfação dos jogadores a partir da aplicação dos modelos GameFlow e PENS. Já no segundo momento, o objetivo foi verificar a satisfação percebida além da diversão e prazer, acrescentando-se também, a satisfação obtida com o conhecimento adquirido. Neste caso, a percepção do jogador sobre o aumento de suas habilidades e conhecimentos na temática apresentada no jogo foi acrescentada ao instrumento GameFlow.

\subsubsection{Primeira Avaliação}

Como foi dito, a primeira avaliação foi realizada com 30 estudantes de graduação e pósgraduação. Para a avaliação do jogo foram necessários alguns procedimentos: 1) Instalação do jogo; 2) Execução do jogo; 3) Seleção da amostra; e 4) Coleta dos dados. Esses procedimentos foram realizados da seguinte forma:

1. Foram enviados para todos os participantes um link da loja Play Store (Loja virtual da Google) contendo o endereço de instalação do jogo;

2. Após instalar o jogo, o participante ficou livre para jogar durante dois dias, sem limitação de tempo de permanência no jogo ou número de vezes de execução.

3. Os participantes foram divididos em dois grupos com o objetivo de responderem os instrumentos da pesquisa, sendo: a) Grupo G1 e, b) Grupo G2. Os jogadores do grupo G1 responderam o instrumento do GameFlow, enquanto os jogadores do grupo G2 responderam o instrumento do PENS. A escolha do participante para a formação do 
grupo foi realizada a partir de uma técnica de amostra probabilística: a amostragem aleatória simples. A amostragem aleatória simples é a técnica de amostragem no qual todos os elementos que compõem o universo amostral têm a mesma probabilidade de serem selecionados para a amostra (Barbetta, 2008). Os participantes foram selecionados aleatoriamente para cada grupo a fim de ter um equilíbrio entre as pessoas que responderiam qualquer um dos instrumentos.

4. Coleta de dados: Todos os instrumentos foram coletados e transferidos para a base de dados da pesquisa através da plataforma de questionários online Google Forms, facilitando o envio e coleta das respostas por parte dos participantes.

Todo o processo avaliativo realizado nesta etapa foi feito de forma online. Os participantes não tiveram problemas relacionados com a instalação do jogo em seus dispositivos, nem quanto ao envio dos dados dos questionários.

\subsubsection{Segunda Avaliação}

Esta avaliação foi realizada em 4 turmas, totalizando 60 estudantes de forma presencial nas dependências da escola. Para cada turma que participou da avaliação foi adotado o seguinte protocolo: a) uma exposição dialogada apresentando a equipe de teste, a importância de mensurar a experiência do jogador em jogos com propósitos, e os objetivos da pesquisa; b) uma apresentação de como ocorreria o desenvolvimento das atividades e c) teste do jogo e aplicação de questionários. Para cada turma o teste teve duração de aproximadamente uma hora. A Tabela 3 apresenta um descritivo dos procedimentos adotados no protocolo de teste.

Tabela 3: Protocolo de teste da segunda avaliação do jogo

\begin{tabular}{lccc}
\hline \multicolumn{1}{c}{ Procedimento } & Participação & $\begin{array}{c}\text { Carga Horária } \\
\text { (minutos) }\end{array}$ & Método \\
\hline Apresentação da equipe & Equipe de teste & 5 & Exposição dialogada \\
Exposição do tema e objetivos da avaliação & $\begin{array}{c}\text { Equipe de teste e } \\
\text { professor da escola }\end{array}$ & 5 & Exposição dialogada \\
Execução do jogo & Alunos & 20 & Execução do jogo \\
Aplicação do questionário de satisfação & Alunos & 10 & Aplicação de instrumento \\
Esclarecimento de dúvidas & Todos & 5 & Exposição dialogada \\
Encerramento & Todos & 5 & Exposição dialogada \\
\hline
\end{tabular}

Com relação ao teste do jogo, os alunos tiveram 20 minutos para testar o jogo sem interrupção da equipe de teste ou professor da escola. Cada aluno testou o jogo individualmente em seu próprio dispositivo móvel garantindo uma experiência individual. Já para a aplicação do instrumento de avaliação, foi realizada apenas uma intervenção inicial para esclarecimento do preenchimento do instrumento.

De forma similar à primeira avaliação, os dados foram coletados e transferidos para a base de dados da pesquisa através da plataforma de questionários online Google Forms. No entanto, em alguns momentos durante o envio e coleta das respostas dos participantes o acesso à internet na escola apresentou oscilação e, em vista disso, alguns questionários foram preenchidos manualmente em formulário de papel.

No final, foi realizado o encerramento no qual a equipe teve a oportunidade de esclarecer dúvidas que não foram sanadas durante o processo de avaliação, bem como, questões relacionadas ao desenvolvimento do jogo e a temática abordada. Todos os testes foram realizados com a 
presença do professor da escola. A Figura 3(a) e 3(b) apresenta alguns momentos da avaliação realizada com os estudantes do ensino médio na escola.

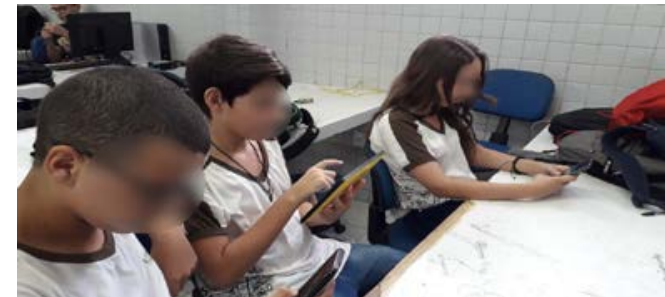

(a)

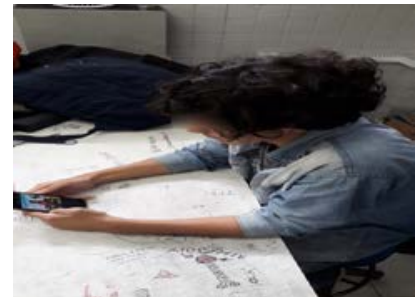

(b)

Figura 3: Avaliação do Caixa de Pandora Mobile com estudantes do ensino médio

\section{Resultados}

Nesta seção serão apresentados os resultados obtidos nas avaliações Caixa de Pandora Mobile a partir dos instrumentos utilizados para mensurar a satisfação percebida dos jogadores.

\subsection{Primeira Avaliação}

Foram coletados $30(n=30)$ questionários, sendo, $15(n=15)$ referentes ao GameFlow, e $15(n=15)$ referentes ao PENS. Dentre os respondentes, predominou o sexo feminino $(n=25,83,33 \%)$ sobre o masculino ( $\mathrm{n}=5,16,67 \%)$. Quanto à idade, a maioria apresentava idade inferior a 35 anos, sendo, $40 \%(n=12)$ até 25 anos, 53,33\% ( $n=16)$ entre 25 e 35 anos, e apenas $6,67 \%(n=2)$ com idade superior a 35 anos.

No que se refere à formação acadêmica, a maioria possuía formação superior incompleta ( $n=15,50 \%)$, seguido de pós-graduação $(n=10,33,33 \%)$ e formação superior completa ( $n=5$, 16,67\%). Quanto à área de atuação, a maioria atua na área da Saúde (n=24, 80\%), seguida da área de Humanas (n=3,10\%), e das áreas de Exatas, Biológicas e Engenharias com 3,33\% (n=1) cada uma. No que diz respeito ao uso de dispositivos móveis, verificou-se que a maioria dos respondentes faz uso de dispositivos móveis com frequência, sendo que 96,67\% (n=29) faz uso diariamente, e 3,33\% ( $n=1)$ faz uso semanalmente, demonstrando que os dispositivos móveis fazem parte do cotidiano dos participantes. Já no que se refere ao uso de jogos digitais, pode-se observar que 46,67\% ( $n=14)$ dos participantes jogam algum tipo de jogo. Desses, $20 \%(n=6)$ utiliza jogos diariamente, $26,67 \%(n=8)$ semanalmente, $40 \%(n=12)$ jogam raramente e apenas $13,33 \%$ (4) nunca jogam.

Tanto o uso de dispositivos móveis quanto o uso de jogos digitais indicaram um real potencial no que diz respeito ao desenvolvimento de jogos com propósito para a área de saúde nas plataformas móveis, haja vista que a maioria dos participantes usam esses dispositivos e fazem uso deles para o entretenimento através dos jogos. A Tabela 4 apresenta uma sumarização das características sociodemográficas e experiência quanto ao uso de dispositivos tecnológicos e de jogos digitais da $1^{\mathrm{a}}$ avaliação. 
Tabela 4: Sumarização dos dados da pesquisa da $1^{\mathrm{a}}$ avaliação

\begin{tabular}{|c|c|c|c|c|c|c|}
\hline \multirow[b]{2}{*}{ Variável } & \multicolumn{2}{|c|}{ GameFlow } & \multicolumn{2}{|c|}{ PENS } & \multicolumn{2}{|c|}{ Total } \\
\hline & $\mathbf{n}$ & $\%$ & $\mathbf{n}$ & $\%$ & $\mathbf{n}$ & $\%$ \\
\hline \multicolumn{7}{|l|}{ Sexo } \\
\hline Masculino & 3 & 20,0 & 2 & 13,3 & 5 & 16,67 \\
\hline Feminino & 12 & 80,0 & 13 & 86,7 & 25 & 83,33 \\
\hline \multicolumn{7}{|l|}{ Faixa Etária } \\
\hline até 25 anos & 8 & 53,3 & 4 & 26,7 & 12 & 40 \\
\hline De 25 até 35 anos & 6 & 40,0 & 10 & 66,7 & 16 & 53,3 \\
\hline Mais de 35 anos & 1 & 6,7 & 1 & 6,7 & 2 & 6,67 \\
\hline \multicolumn{7}{|l|}{ Formação Acadêmica } \\
\hline Superior Incompleto & 9 & 60,0 & 6 & 40,0 & 15 & 50 \\
\hline Superior Completo & 1 & 6,7 & 4 & 26,7 & 5 & 16,67 \\
\hline Pós-graduação & 5 & 33,3 & 5 & 33,3 & 10 & 33,33 \\
\hline \multicolumn{7}{|l|}{ Dispositivos Móveis } \\
\hline Diariamente & 15 & 100,0 & 14 & 93,3 & 29 & 96,67 \\
\hline Semanalmente & - & - & 1 & 6,7 & 1 & 3,33 \\
\hline Raramente & - & - & - & - & 0 & 0 \\
\hline Nunca & - & - & - & - & 0 & 0 \\
\hline \multicolumn{7}{|l|}{ Uso de Jogos } \\
\hline Diariamente & 3 & 20,0 & 3 & 20,0 & 6 & 20 \\
\hline Semanalmente & 5 & 33,3 & 3 & 20,0 & 8 & 26,67 \\
\hline Raramente & 5 & 33,3 & 7 & 46,7 & 12 & 40 \\
\hline Nunca & 2 & 13,3 & 2 & 13,3 & 4 & 13,33 \\
\hline
\end{tabular}

Inicialmente foi conduzido um teste para verificar o poder discriminatório dos instrumentos do GameFlow (G1) e PENS (G2). Para tanto, foi realizado o teste de fidedignidade a partir da análise de consistência interna (Alpha de Cronbach). A Tabela 5 apresenta a consistência interna analisada por meio dos escores do $\alpha$ Cronbach. Esta análise demonstrou valores significativos $(\geq 0,70)$ para os dois instrumentos, tanto para o GameFlow $(\alpha=0,94)$ quanto para o PENS $(\alpha=0,87)$. Assim, observa-se que a fidedignidade é aceitável para a adequação dos instrumentos a esta população.

Por se tratar de dois grupos independentes e com amostras pequenas, foi aplicado o teste não paramétrico de Mann-Whitney. O valor-p do teste de Mann-Whitney para os valores padronizados dos dois grupos foi de 0,935 mostrando que não há diferença significativa entre os grupos quanto à satisfação observada com estes dois instrumentos. Deste modo, tanto o instrumento GameFlow quanto o PENS não apresentam diferenças significativas na mensuração da satisfação percebida pelo jogador em relação a sua experiência no jogo Caixa de Pandora Mobile. Isso demonstra que os dois instrumentos apresentaram avaliações semelhantes no que se refere à satisfação do jogador. 
Tabela 5: Fidedignidade alpha Cronbach para os grupos G1 e G2

\begin{tabular}{lcc}
\hline \multicolumn{1}{c}{ Instrumento } & Alpha de Cronbach & IC 95\%* \\
\hline G1 - GameFlow & 0,942 & 0,889 a 0,977 \\
G2 - PENS & 0,874 & 0,757 a 0,950
\end{tabular}

*Intervalo de confiança

A Figura 4 ilustra os resultados referentes à satisfação dos jogadores no que diz respeito às dimensões do GameFlow. Observa-se que a maioria das dimensões foram muito bem avaliadas, sendo a dimensões "Desafios" o que apresentou a maior média $(4,49)$ entre os demais. No que diz respeito a "Concentração", (Sweetser \& Wyeth, 2005) recomenda que os jogos devem exigir concentração e o jogador deve se concentrar no jogo. Alguns elementos do jogo podem influenciar nos níveis de concentração, como por exemplo: a qualidade gráfica, cenas envolventes, carga de trabalho compatível com as habilidades dos jogadores, entre outros. O resultado obtido na avaliação da dimensão “Concentração" aponta que o Caixa de Pandora está indo na direção certa no sentido de maximizar a concentração do jogador.

A dimensão “Habilidades” também obteve bons resultado apresentando média de 4,21. O destaque sobre a dimensão "Desafios" e "Habilidades" no Caixa de Pandora é um aspecto relevante e corrobora o trabalho de Ryan et al. (2006), no qual os autores consideram que um dos principais precursores de uma experiência prazerosa é a combinação entre habilidades dos jogadores e os desafios que são propostos pelo jogo. A dimensão "Controle” obteve média de 4,21, essa dimensão avalia principalmente a sensação de controle do jogador sobre suas ações no jogo (Sweetser \& Wyeth, 2005), o Caixa de Pandora fornece uma mecânica simples com controles intuitivos, o que neste caso, pode ter contribuído para uma avaliação positiva. Com relação aos "Objetivos”, o jogo fornece ao longo de sua execução os objetivos de cada nível a ser explorado, facilitando o entendimento do jogador. Quanto ao "Feedback", o jogo obteve um bom resultado. Para Ryan et al. (2006), o feedback é um mecanismo importante, pois o jogador precisa receber resposta do jogo no momento apropriado.

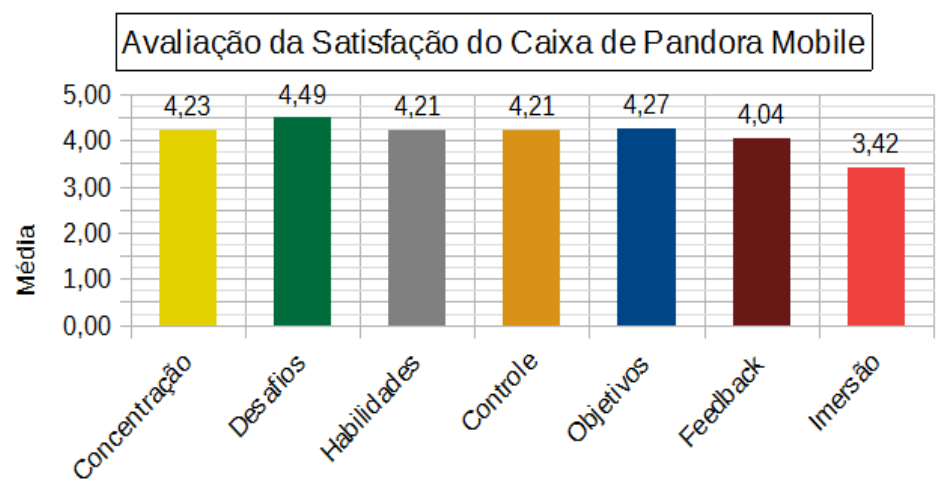

Dimensões GameFlow

Figura 4: Avaliação das dimensões GameFlow

Já a dimensão "Imersão" apresentou a menor média $(3,42)$ ficando abaixo das outras dimensões avaliadas. Nesse sentido, os dados serão avaliados com objetivo de verificar o que pode ser potencializado no jogo para proporcionar uma maior sensação de imersão.

Os resultados obtidos sobre a satisfação dos jogadores através do instrumento PENS apresentou também bons resultados (Figura 5), corroborando os achados do instrumento GameFlow. O componente "Competência” apresentou os melhores resultados, produzindo média de 6,13. Para Ryan e Deci (2000) a competência expressa o sentimento de domínio ou efetividade 
no que se está fazendo. O sentimento de competência diante de um problema ou tarefa pode energizar e motivar a realizar ações adicionais, enquanto o sentimento de ineficácia diminui a motivação e traz um impacto psicológico negativo (Rigby \& Ryan, 2007; Przybylski et al., 2010). Assim, oportunizar fatores (por exemplo, feedback positivo, desafios ótimos, etc.) que possam melhorar a experiência de competência, é segundo (Ryan et al., 2006; Ryan \& Deci, 2000) uma forma aumentar a competência percebida e, por sua vez, a motivação intrínseca. Assim, a avaliação recebida pelo jogo no componente "Competência”, dá indícios que o jogo possibilita uma boa experiência de competência.

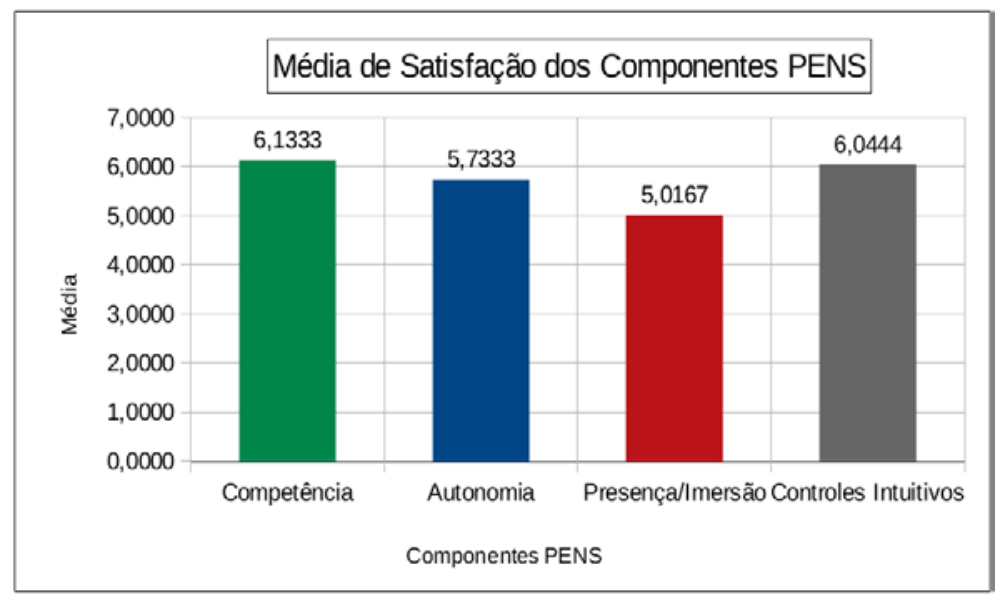

Figura 5: Avaliação dos componentes PENS

No que se refere à “Autonomia”, Rigby e Ryan (2007) mencionam que ela está relacionada com a escolha das suas próprias decisões e ações que são realizadas pelo jogador. Segundo Karkowski et al. (2016), o sentimento de liberdade para escolher e criar as suas próprias experiências durante o jogo pode motivar intrinsecamente o jogador a se engajar. Quando as atividades são feitas por interesse ou valor pessoal, a autonomia percebida é alta (Ryan et al., 2006). Maximizar as oportunidades de ação do jogador pode gerar maior sensação de autonomia e, por sua vez, a motivação intrínseca (Ryan et al., 2006; Rigby \& Ryan, 2007). No escopo do jogo, o Caixa de Pandora propicia bons níveis de autonomia, de modo que o jogador é livre para tomar suas decisões como, por exemplo, rever a apresentação dos passatempos (desafios) pelo tempo que for necessário. A “autonomia” no Caixa de Pandora foi bem avaliada, obteve média de 5,73. No entanto, a partir da avaliação foi possível identificar que existem aspectos importantes que podem contribuir para uma maior autonomia como, por exemplo, controle temporal dos passatempos e mecanismo de seleção das respostas por parte dos jogadores.

O componente "Presença/Imersão" apresentou resultados semelhantes ao componente “Imersão” do GameFlow e obteve os menores índices de satisfação avaliado pelos jogadores, com uma média de 5,01. Tanto o GameFlow quanto o PENS avaliam aspectos referentes à presença emocional, física e narrativa. Neste aspecto, o jogo Caixa de Pandora não disponibiliza dispositivos que permitam oferecer as sensações de presença física, o que pode ter ocasionado a má avaliação desta dimensão. Quanto aos “Controles Intuitivos”, o jogo obteve uma média 6,04. Neste quesito, sabe-se que o jogo oferece controles de fácil uso, não exigindo esforço de adaptação por parte do jogador. Para Ryan et al. (2006), os controles intuitivos podem contribuir para a motivação do jogo, pois estão associados a uma maior sensação de liberdade e controle, bem como aumentam o senso de competência.

Sugestões para melhoria do jogo foram apresentadas pelos jogadores. Foram elas: "Deixar a trilha sonora do jogo mais agradável”, "Opção para confirmar a resposta das perguntas, evitando a seleção acidental de uma resposta" e "Possibilidade de pausar as cenas do passatempo para uma melhor avaliação". Essas questões abordadas pelos jogadores podem ter de alguma forma 
dificultado a imersão emocional dos jogadores durante a execução do jogo. A imersão emocional reflete justamente o quão fortemente conectados os jogadores do jogo se sentiram (Ryan et al., 2006; Przybylski et al., 2010).

\subsection{Segunda Avaliação}

Dos sessenta $(n=60)$ questionários aplicados na escola, apenas $45(n=45)$ foram coletados para a pesquisa, de modo que, 15 questionários foram descartados em virtude de erros associados ao preenchimento, tais como: ausência de dados, perguntas com duas ou mais respostas, dentre outras. Dos $45(n=45)$ questionários coletados na amostra final, 57,8\% $(n=26)$ eram do sexo feminino e 42,2\% ( $n=19)$ do masculino. Quanto à idade, a maioria apresentava idade entre 16 e 17 anos (n=29, 64,4\%), seguido de, 31,1\% ( $n=14)$ com idade entre 14 e 15 anos, e 4,4\% (n=2) acima dos 17 anos. No que se refere ao uso de dispositivos móveis, verificou-se que a maioria dos respondentes faz uso de dispositivos móveis com bastante frequência, sendo que, 95,6\% ( $n=43)$ faz uso diariamente, 2,3\% ( $n=1)$ faz uso semanalmente, e apenas 2,2\% $(n=1)$ nunca faz uso destes dispositivos, assim, fica evidente que os dispositivos móveis fazem parte do cotidiano dos respondentes. Quando perguntados sobre o uso de jogos digitais, verificou-se que $31,1 \%(n=14)$ jogam diariamente, 28,9\% ( $n=13)$ jogam semanalmente, 37,8\% $(n=17)$ jogam raramente e apenas $2,2 \%(n=1)$ nunca jogam.

De forma similar aos resultados encontrados na primeira avaliação, é possível sugerir que o uso de dispositivos móveis e uso jogos digitais fazem parte do cotidiano dos respondentes, e deste modo, também indicam um real potencial no que diz respeito ao desenvolvimento de jogos com propósito nas plataformas móveis, seja para capacitação de estudantes e profissionais da área da saúde como é o caso dos participantes da primeira avaliação, ou para ensino-aprendizagem em escola de ensino médio, que é caso dos participantes da segunda avaliação. A Tabela 6 apresenta uma sumarização das características sociodemográficas e experiência quanto ao uso de dispositivos tecnológicos e de jogos digitais da $2^{\mathrm{a}}$ avaliação.

Tabela 6: Sumarização dos dados da pesquisa da $2^{\mathrm{a}}$ avaliação

\begin{tabular}{lcc}
\hline Variáveis e Categorias & $\mathbf{n}$ & \% \\
\hline Sexo & 19 & 42,2 \\
Masculino & 26 & 57,8 \\
Feminino & & 31,1 \\
Faixa Etária & 14 & 64,4 \\
14 até 15 anos & 29 & 4,4 \\
16 até 17 anos & 2 & \\
Mais de 17anos & & 95,6 \\
Dispositivos Móveis & 43 & 2,2 \\
Diariamente & 1 & 0 \\
Semanalmente & 0 & 2,2 \\
Raramente & 1 & 31,1 \\
Nunca & 14 & \\
Uso de Jogos & & \\
Diariamente & & \\
\end{tabular}




\begin{tabular}{lcc} 
Semanalmente & 13 & 28,9 \\
Raramente & 17 & 37,8 \\
Nunca & 1 & 2,2 \\
\hline
\end{tabular}

A Tabela 7 apresenta as médias obtidas a partir das experiências dos jogadores no jogo. Em destaque, a dimensão "Objetivos" com a maior média $(\mathrm{M}=4,44, \mathrm{DP}=0,66)$ e demais dimensões que foram bastante equivalentes. Em geral, valores médios altos de cada dimensão indicam que o jogo forneceu as circunstâncias apropriadas para potencializar a experiência do jogador no jogo (Kiili et al., 2012). Dentre elas destaca-se: a melhoria do conhecimento, os desafios, o controle, e o feedback alcançando os maiores valores.

Tabela 7: Médias e desvios padrão das dimensões do GameFlow

\begin{tabular}{ccc}
\hline Dimensões do GameFlow & Média & Desvio Padrão \\
\hline Concentração & 3,88 & 0,71 \\
Desafios & 4,30 & 0,74 \\
Habilidades & 3,90 & 0,66 \\
Controle & 4,16 & 0,72 \\
Objetivos & 4,44 & 0,66 \\
Feedback & 4,07 & 0,82 \\
Imersão & 3,34 & 1,20 \\
Conhecimento & 4,38 & 0,75 \\
\hline
\end{tabular}

A confiabilidade do questionário GameFlow utilizado indica que as dimensões do GameFlow são internamente consistentes. A Tabela 8 apresenta a consistência interna analisada por meio dos escores do coeficiente $\alpha$ Cronbach. Através da análise foi possível verificar valor significativo $(\geq 0,70)$ para o instrumento, ou seja, $\alpha=0,903$ com intervalo de confiança de $95 \%$. Assim, observa-se que a fidedignidade é aceitável para a adequação do instrumento a esta população.

Tabela 8: Fidedignidade alpha Cronbach para GameFlow Adaptado

\begin{tabular}{ccc}
\hline Instrumento & Alpha de Cronbach & IC 95\%* \\
\hline GameFlow Adaptado & 0,903 & 0,857 a 0,940 \\
\hline
\end{tabular}

*Intervalo de confiança

Como pode-se observar na Figura 6, os resultados obtidos pelo jogo Caixa de Pandora Mobile na avaliação das dimensões do GameFlow foram bem satisfatórios na sua grande maioria, corroborando os resultados da primeira avaliação. Observa-se que o jogo foi bem avaliado apontando que, mesmo com perfis de jogadores distintos, os resultados da mensuração da satisfação e experiência do jogador no jogo apontam para a mesma direção.

Com relação às dimensões avaliadas, “Objetivos” apresentou o melhor resultado entre os demais com média de 4,44. Esse resultado é bem próximo ao resultado obtido na primeira avaliação com média de 4,27. A clareza dos objetivos é algo importante, pois segundo Sweetser et al. (2017), eles podem fornecer aos jogadores uma compreensão clara da estória do jogo, bem como a justificativa para as ações do jogador. 


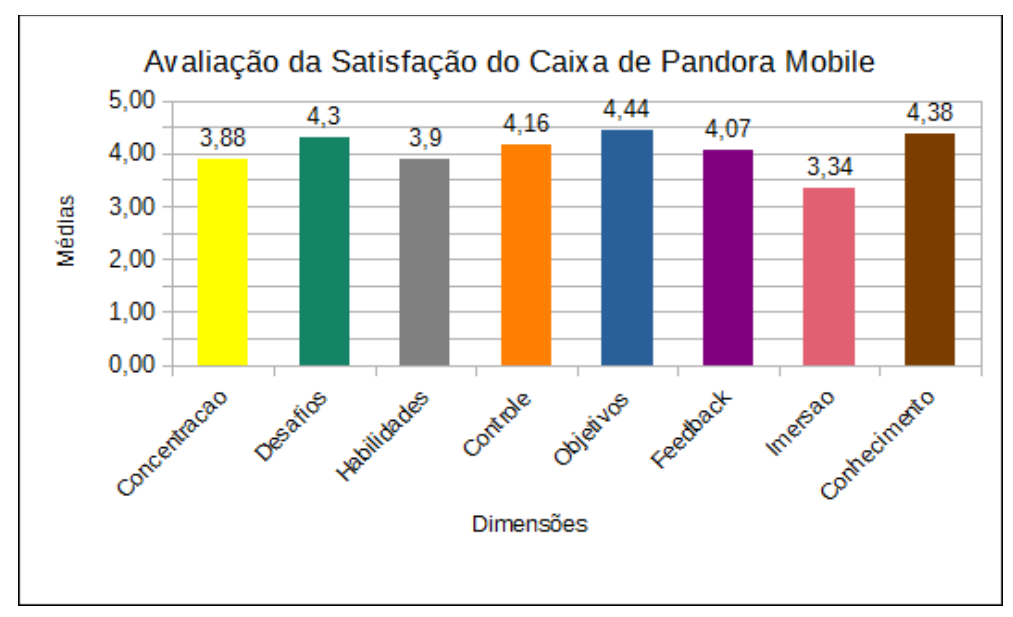

Figura 6: Avaliação da Satisfação do Caixa de Pandora Mobile

A dimensão "Conhecimento" ou "Melhoria de Conhecimento" foi avaliada com média de 4,38, sendo a segunda melhor média. Ela analisou a opinião dos jogadores no tocante a percepção de aprendizagem sobre a temática da violência doméstica contra a mulher. Essa dimensão diz respeito ao quanto o jogador aumenta o seu nível de conhecimento e suas habilidades com relação ao conteúdo educacional proposto (Fu et al., 2009). O bom desempenho nesta dimensão pode indicar que a partir das modificações realizadas no jogo no processo de redesign, o jogo pode ser utilizado não apenas para treinamento e capacitação de profissionais de saúde, mas também, como ferramenta pedagógica para diferentes tipos de jogadores. Deste modo, obter uma boa avaliação dos estudantes do ensino médio nesta dimensão, é um indício de que o jogo Caixa de Pandora está na direção certa no que diz respeito a compreensão e uso dos conceitos relacionados com a temática do jogo. Por exemplo, a pergunta K4 (quadro 4) "K4. O jogo me motivou a usar o conhecimento adquirido no dia a dia.” obteve média 4,53, sendo a maior nota dentre os itens da dimensão, sugerindo que o jogo pode ser utilizado como ferramenta de transformação/construção do conhecimento conforme os resultados encontrados por Almeida et al. (2018).

No que se refere à dimensão "Desafios”, que no Caixa de Pandora Mobile são chamados de “passatempos”, foram projetados de tal maneira que fossem apresentados do mais simples ao mais complexo sem sobrecarregar o jogador, tentando lhe manter sempre envolvido ou engajado no jogo. Essa estratégia de design possibilitou uma boa avaliação dos jogadores nesta dimensão com média de 4,30. Outro aspecto a observar na avaliação foi a dimensão "Controle”, que obteve média 4,16. Essa dimensão avalia principalmente o controle dos mecanismos que são utilizados pelo jogador para executar as suas ações no jogo (Sweetser et al., 2017), por exemplo, o controle na manipulação das telas, botões, menus e demais elementos do universo jogo, até o controle sobre o andamento do jogo (iniciar, parar, sair do jogo). O processo de redesign do Caixa de Pandora Mobile possibilitou a modificação de alguns elementos da mecânica do jogo, tais como, a temporização dos passatempos, aleatoriedade da exibição das respostas dos passatempos, e maior gerência sobre as alternativas das respostas. Essas modificações potencializam o controle do jogador, e pode ter contribuído para uma boa avaliação da dimensão "Controle”.

Outra dimensão bem avaliada foi "Feedback" com média 4,07. Esta dimensão avalia principalmente se o jogo fornece informações adequadas sobre as ações e o progresso do jogador (Fu et al., 2009; Sweetser et al., 2017). Feedback compõem técnicas eficazes que podem apoiar os jogadores na seleção de informações relevantes no decorrer do jogo (Wouters \& Van, 2017). Em grande parte dos jogos, os feedbacks são utilizados para indicar se a ação do jogador estar correta ou não, por exemplo, em jogos com propósitos educativos o jogo pode verificar se a resposta dada pelo jogador está exatamente condizente com o conteúdo educacional, ou explicar o porquê de não estar correta. No Caixa de Pandora Mobile, os feedbacks são apresentados de 
forma reflexiva, não existe "o certo” ou “o errado”, mas sim uma reflexão sobre a postura do jogador diante da temática apresentada (motivar o jogador a se engajar ativamente).

Quanto à dimensão "Habilidades”, o jogo obteve média 3,90. Essa média é inferior à média obtida pelo jogo na $1^{a}$ avaliação que foi de 4,21. A dimensão "Habilidades" trabalha na perspectiva de o jogador desenvolver suas habilidades enquanto joga (Sweetser et al., 2017) e, desta maneira, avalia elementos no jogo que possam potencializar essas habilidades. Apesar de existir um help (manual de instruções), o jogo obteve a menor média $(m=3,0)$ neste quesito (item H3 do quadro 4), indicando a necessidade de uma melhor análise deste item em função do perfil dos jogadores (jovens entre 14 e 18 anos). No entanto, os itens H5 e H7 que tratam da evolução do conhecimento do jogador e da facilidade e compreensão dos passatempos (desafios) do jogo foram muito bem avaliados, com média 4,36 e 4,40, respectivamente. Já com relação à dimensão “Concentração”, a média obtida foi de 3,88. Esta dimensão busca averiguar quão concentrado o jogador está nas tarefas apresentadas no jogo. Diversos elementos do jogo podem influenciar na concentração do jogador, desde elementos audiovisuais (cenas, trilha sonora, etc.) até o balanceamento entre desafios e habilidades do jogador (Kiili et al., 2012). Nos itens que compõem esta dimensão, o item C3 (quadro 4) trata da sobrecarga de trabalho sentida pelo jogador enquanto joga. Nesta avaliação este item obteve a menor média $(m=3,40)$ dentre os itens da dimensão. Uma das possíveis causas deste resultado se deve ao fato de que no nível 3 do jogo os passatempos (desafios) focam, principalmente, nas práticas (acolhimento, atendimento médico, etc) dos profissionais de saúde quanto à atenção oferecida à mulher em situação de violência. Portanto, parte desses passatempos abordam conceitos complexos que precisam de uma formação especializada.

Por fim, pode-se observar o resultado da dimensão “Imersão”. A imersão no GameFlow avalia principalmente o envolvimento emocional dos jogadores. No jogo Caixa de Pandora Mobile, essa dimensão não obteve um bom resultado, alcançando apenas uma média de 3,34. Esse resultado é semelhante ao obtido na $1^{\underline{a}}$ avaliação do jogo. Portanto, eles sugerem que os aspectos relacionados com a imersão dos jogadores no jogo precisam ser analisados, e sobretudo, potencializados. Fazendo uma análise preliminar, observa-se que alguns fatores podem ter comprometido a imersão do jogador, como, por exemplo, a concentração. Segundo Audi (2014) a imersão não é sinônimo de atenção ou concentração. No entanto, sem a concentração devida, o jogo não conseguirá criar um mundo atrativo que possa transportar o jogador para o mundo virtual e para dentro da estória do jogo, de modo que esse jogador possa sentir-se fisicamente ou virtualmente parte da experiência.

Por fim, foi solicitado aos jogadores sugestões para a melhoria do jogo. A maioria achou que o jogo estava bom e que não precisava de alterações. Porém, foram apresentadas algumas sugestões, tais como: "Reduzir a quantidade de informações na tela por se tratar de uma aplicação mobile"; "Trilha sonora cansativa - Melhorar a trilha sonora”, "Deixar o usuário parametrizar o tempo de exibição de cada cena nos passatempos", e por fim, "Desenvolver um RPG (do inglês Role-playing game) com a mesma temática”.

\subsection{Discussão}

A partir dos resultados demonstrados e discutidos nas seções 4.1 e 4.2, foi possível observar que a satisfação percebida pelo jogador a partir da experiência de jogo foi satisfatória. Quando se observa os resultados das avaliações por dimensão, verifica-se que na sua maioria elas foram bem avaliadas, sugerindo uma correlação positiva entre a qualidade da experiência dos alunos e os resultados de aprendizagem, corroborando os achados de Fu et al. (2009) e Kiil (2012).

Em síntese, pode-se observar a partir da Figura 7 que independentemente do público-alvo que foi avaliado com o Caixa de Pandora Mobile, os resultados apontam para a mesma direção. Portanto, o resultado do uso dos instrumentos sugere semelhança nos pontos que são fortes e que 
podem potencializar a experiência do jogador no jogo, ao passo que, apontam também para outros pontos que poderiam ser trabalhados no sentido de fortalecer ainda mais a experiência dos jogadores, e com isso, ampliar as chances de maior engajamento.

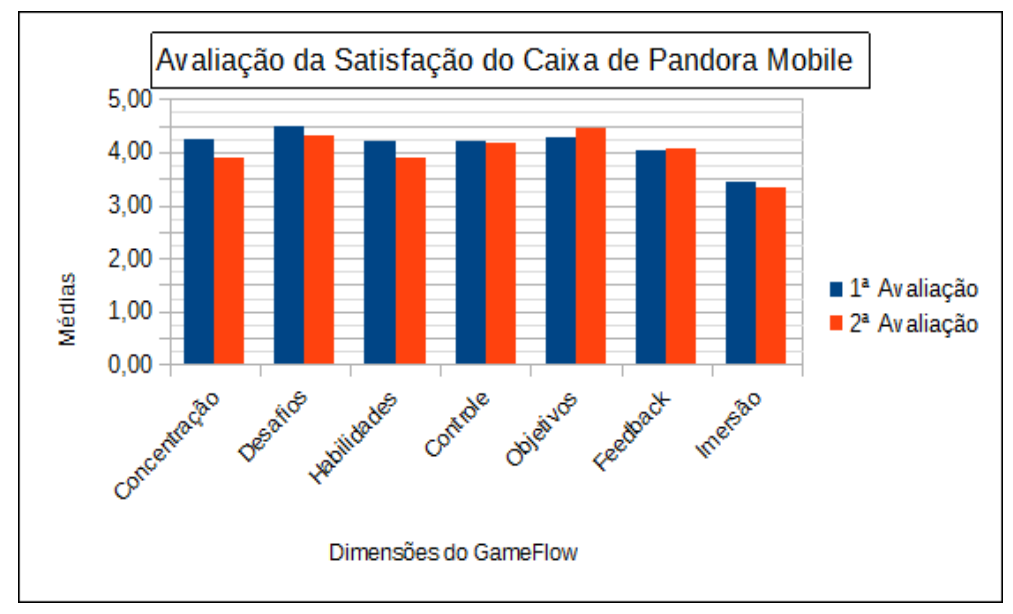

Figura 7: Comparativo das Avaliações de Satisfação do Caixa de Pandora Mobile

Através de uma análise mais detalhada dos itens que constituem as dimensões dos modelos, foi possível definir heurísticas para o processo de redesign do Caixa de Pandora Mobile e, fazer um olhar mais criterioso nos elementos de design que compõe o jogo. Várias dessas heurísticas foram utilizadas no redesign como por exemplo a adequação da linguagem utilizada nos desafios do jogo. Esta mudança foi necessária principalmente para equilibrar as dificuldades dos desafios com as habilidades dos jogadores, uma vez que, se pretendia disponibilizar o jogo para o público em geral e não apenas profissionais da saúde. Neste caso, esse equilíbrio pode fortalecer o sentimento de competência do aluno (jogador) motivando-o a progredir no jogo, como também, a permanecer jogando por maior tempo. Por outro lado, quando existe um desequilíbrio é possível que o aluno sinta tédio (tarefas fáceis) ou frustração (tarefas difíceis), provocando um desinteresse ou uma desmotivação natural pelo jogo. Em práticas educativas que utilizam jogos como ferramenta pedagógica, é fundamental que existam bons níveis de aceitação pelo aluno. De acordo Whitton (2010), ele deve estar motivado a utilizar o jogo não apenas no âmbito escolar, mas também no lazer como uma experiência de aprendizado, partindo de uma motivação extrínseca para uma motivação intrínseca. Em outras palavras, quanto mais sentido o aluno percebe na tarefa, mais autônomo se torna e melhor é a sua qualidade motivacional.

Ainda com relação a avaliação, outro ponto que pode ter contribuído para qualificar a experiência de jogo foi a “estória”. A “estória” é avaliada sob o prisma do envolvimento emocional do jogador na dimensão de imersão, no caso do Caixa de Pandora, ela descreve uma situação da vida real frequentemente encontrada. Os alunos podem se relacionar naturalmente com relatos ou com experiências pessoais enquanto se conectam ao conteúdo da aprendizagem. A "estória" pode envolver emocionalmente os alunos potencializando a sensação de "imersão e presença”, bem como, afetar os aspectos afetivos do aluno. As emoções afetam significativamente a percepção, a tomada de decisões e o aprendizado segundo Argasiński e Węgrzyn (2018). Para os autores, a motivação, o engajamento, a excitação, o tédio e, frustração são exemplos de estados afetivos que influenciam o aprendizado de alguma forma. Por exemplo, segundo Wilkinson (2013), a frustração pode influenciar negativamente no processo de aprendizagem, em contraste, a motivação pode criar estados afetivos positivos, pois, quando emocionalmente motivado maiores são as chances de engajamento e concentração nas ações relevantes da atividade (Argasiński \& Węgrzyn, 2018). Assim, é papel dos desenvolvedores de jogos procurar criar experiências envolventes com conteúdos emocionalmente relevantes que possam potencializar as 
habilidades afetivas do jogador proporcionando maior reflexão e possibilidades de um aprendizado mais efetivo.

Os modelos de avaliação utilizados neste trabalho são baseados em teorias da motivação humana (teoria do Flow e a teoria da autodeterminação), e mostram que a motivação do jogador depende dos “desafios" de uma "experiência” envolvente correspondente às "habilidades" do jogador para alcançar os “objetivos” estabelecidos. Todo o arcabouço teórico dos modelos pode ser utilizado não apenas para mensurar a satisfação do jogador mas também como um conjunto de ideias base para modificar os elementos de design do jogo e fortalecer o seu propósito. No caso do Caixa de Pandora Mobile, o propósito foi fortalecer o processo de aprendizagem para um público-alvo além dos profissionais de saúde.

Como foi observado nos trabalhos relacionados, geralmente a experiência de jogo do jogador é avaliada apenas uma única vez, são poucos os trabalhos que após um redesign ou manutenção apresentam novas avaliações. Como dito, é fundamental averiguar se as mudanças realizadas proporcionam os efeitos desejados, principalmente no que diz respeito a melhoria do conhecimento em jogos com propósitos educacionais. Neste estudo, embora os resultados da primeira avaliação tenham sugerido bons níveis de satisfação, foi importante mensurar novamente a experiência e verificar se as mudanças promoveram os resultados esperados.

Outro ponto importante que foi considerado neste trabalho foi a escolha e o número de técnicas para a avaliação. Do ponto de vista da escolha, ambas as técnicas escolhidas utilizam a motivação humana como base, sendo a motivação um dos principais componentes para o processo de aprendizagem como pode ser visto no trabalho de Ryan e Deci (2000). Já com relação ao número, foram utilizadas duas técnicas pelas seguintes razões: 1) verificar se os resultados das técnicas apontam na mesma direção; 2) obter um maior detalhamento e abrangência dos elementos de design, ou seja, elementos que não são observados em uma podem ser na outra. Desta maneira, o objetivo foi cobrir o maior número de elementos de design do jogo que pudessem melhorar a experiência e fortalecer a aprendizagem do jogador.

Fazendo uma reflexão do ponto de vista educacional, os resultados das avaliações podem servir de parâmetro para analisar se o projeto do jogo com propósito educacional permitiu o desenvolvimento de um produto que alcançou as expectativas previstas, tal qual ocorre no desenvolvimento de um plano de ensino tradicional, ao se planejar uma disciplina. Segundo Fonseca e Fonseca (2007), alguns pontos podem ser considerados em um plano de ensino, e esses pontos podem ser visualizados e ou mapeados nos elementos de design do jogo que são abordados pelos modelos de avaliação deste estudo. Para Fonseca e Fonseca (2007), um bom plano deve: a) apresentar os objetivos passíveis de serem executados (Objetivos claros); b) utilizar recursos que favorecem a sua execução (Elementos de Concentração, Habilidade dos jogadores, controle, feedback, imersão); c) propor conteúdos que permitam alcançar os objetivos propostos (Desafios); d) atribuir às atividades, tempo que permita o desenvolvimento e aprendizagem dos conteúdos, em seus diversos níveis de complexidade (Desafios). Assim, pode-se refletir que a análise dos resultados das avaliações pode amparar a equipe (game designer, especialista educacional, dentre outros) no processo de redesign de maneira mais efetiva no acoplamento entre conteúdo pedagógico e elementos da tétrade (mecânica, narrativa, estética, e tecnologia), objetivando as expectativas esperadas com o jogo.

Ao se integrar o conteúdo educacional aos demais elementos de design, qualquer alteração demandará em um novo processo de avaliação da satisfação. Entende-se que algumas abordagens, como a de Eckardt e Robra-Bissantz (2019) não fazem essa integração do conteúdo aos demais elementos, o que não demanda uma nova avaliação da satisfação completa, mas eventualmente apenas a avaliação do aspecto educacional, como nas questões aqui abordadas do EGameFlow. Sendo assim, os resultados obtidos na avaliação do jogo com propósito educacional Caixa de Pandora Mobile, sugerem que o uso da técnica PENS, bem como a do Gameflow (com a dimensão 
"Melhoria do Conhecimento" do EGameFlow), podem ser utilizadas para a avaliação da satisfação em jogos educacionais, oferecendo resultados similares.

Por fim, para entender melhor as experiências e o desempenho dos alunos obtidos nesse trabalho, acreditamos que mais pesquisas com um tamanho maior de amostra e observação a longo prazo podem ser necessárias. Uma limitação encontrada neste estudo foi o uso de amostras com tamanho relativamente pequeno em ambas as avaliações, 30 estudantes $(n=30)$ na primeira avaliação e $60(n=60)$ na segunda. Assim, julgamos que uma amostra maior e mais representativa seria uma consideração importante em estudos futuros.

\section{Conclusão}

O presente trabalho utilizou dois modelos distintos de avaliação com o objetivo de verificar e esclarecer quais aspectos poderiam ser melhorados no Caixa de Pandora Mobile para fortalecer o engajamento no jogo. Os modelos foram, o PENS que usa uma abordagem psicológica (competência, autonomia e relacionamento), e o GameFlow que trabalha com uma perspectiva mais focada no divertimento. Além disso, esse trabalho também procurou analisar se o jogo amplia o conhecimento e as habilidades dos jogadores no conteúdo educacional proposto.

A realização dos testes estatísticos revelou que não existiu diferença significativa entre os grupos quanto à satisfação observada. Deste modo, tanto o PENS quanto o GameFlow apontaram para resultados semelhantes no que diz respeito à satisfação. O Caixa de Pandora Mobile foi avaliado de forma satisfatória, apresentando bons resultados em ambos os modelos e em ambas as avaliações. A partir das avaliações foi possível observar que mesmo com perfis de jogadores distintos, os resultados da mensuração da satisfação e experiência do jogador no jogo apontam para a mesma direção. As avaliações também indicaram pontos que precisam ser fortalecidos no jogo. Outro achado importante foi a boa avaliação que o jogo obteve no aspecto relacionado com a melhoria dos conhecimentos dos jogadores com relação ao conteúdo educacional apresentado. Esse dado é relevante nesta pesquisa, pois sugere que o jogo pode ser usado como uma ferramenta para promover o conhecimento de estudantes em um tema bastante importante que é a violência doméstica contra a mulher, e que apresenta atualmente estatísticas alarmantes no Brasil. Na versão anterior do Caixa de Pandora, Almeida et al. (2014; 2018) já tinha evidenciado o potencial da ferramenta na promoção do conhecimento, sendo mais uma vez destacado aqui nessa pesquisa. De forma complementar, foi possível observar neste trabalho a satisfação percebida dos jogadores no conhecimento adquirido.

É importante a adoção de técnicas de avaliação que possam contribuir para o processo de design, de maneira que, o jogo atenda o propósito para qual foi desenvolvido. Neste caso, atender ao propósito relaciona-se ao objetivo da aplicação. Quando este objetivo é educacional, a obtenção da satisfação potencializa o uso da utilidade percebida, ou seja, vai além do momento em que o aluno é solicitado a usar o jogo. Este processo está diretamente ligado ao engajamento do jogador (Csikszentmihalyi, 1999). Os apontamentos descritos nos resultados e discussões do presente trabalho permitem verificar que a avaliação da satisfação sob o olhar dos modelos PENS e GameFlow podem contribuir com o processo de refinamento da qualidade de um serious game quanto à sua capacidade de promover engajamento, fornecendo dados de aspectos do jogo que podem ser trabalhados com o objetivo de aumentar a satisfação do jogador. Como próximo passo da presente pesquisa, pretende-se explorar elementos de imersão de modo a verificar seu impacto na satisfação e na promoção do conhecimento. 


\section{Referências}

Almeida, L. R., Machado, L. S., \& Medeiros, A. T. (2014). Serious game sobre violência contra a mulher: uma avaliação com profissionais de saúde. SBC-Proceedings of SBGames 2014, 567-575. [GS SEARCH]

Almeida, L. R., Machado, L. S., Medeiros, A. T., Coelho, H. F., Andrade, J. M., \& Moraes, R. M. (2018). The caixa de pandora game: Changing behaviors and attitudes toward violence against women. Computers in Entertainment (CIE), 16(3), 1-13. DOI:https://doi.org/10.1145/3236493 [GS SEARCH]

Audi, G., \& Régis, F. (2014). Imersão em jogos narrativos de videogame/Immersion in narrative video games. Revista Contracampo, (29), 65-83. [GS SEARCH]

Argasiński, J. K.; Węgrzyn, P. (2018). Affective patterns in serious games. Future Generation Computer Systems, v. 92, 526-538. DOI:https://doi.org/10.1016/j.future.2018.06.013 [GS $\underline{\text { SEARCH] }}$

Barbetta, P. A. (2006). Estatística Aplicada às Ciências Sociais. 6ª Ed. Florianópolis: Ed. UFSC.

Barbosa, S., \& Silva, B. (2010). Interação humano-computador. Elsevier Brasil.

Birk, M., \& Mandryk, R. L. (2013). Control your game-self: effects of controller type on enjoyment, motivation, and personality in game. In Proceedings of the SIGCHI Conference on Human Factors in Computing Systems, (pp. 685-694). ACM. DOI:https://doi.org/10.1145/2470654.2470752 [GS SEARCH]

Cairns, P. (2016). Engagement in digital games. In Why Engagement Matters (pp. 81-104). Springer, Cham. DOI:https://doi.org/10.1007/978-3-319-27446-1_4 [GS SEARCH]

Carvalho, R. N. S. D., \& Ishitani, L. (2013). Fatores motivacionais para desenvolvimento de mobile serious games com foco no público da terceira idade: uma revisão de literatura. ETDEducação Temática Digital, 15(1), 16-32. [GS SEARCH]

Csikszentmihalyi, mihaly. (1999). A descoberta do fluxo: a psicologia do envolvimento com a vida cotidiana. Rio de janeiro: Rocco.

Denisova, A., Nordin, A. I., \& Cairns, P. (2016). The convergence of player experience questionnaires. In Proceedings of the 2016 Annual Symposium on Computer-Human Interaction in Play (pp. 33-37). DOI:https://doi.org/10.1145/2967934.2968095 [GS $\underline{\text { SEARCH] }}$

Dias, J. D., Mekaro, M. S., Lu, J. K. C., Tsuda, G. S. S. M., Otsuka, J. L., Beder, D. M., \& ZemMascarenhas, S. H. (2016). Design e avaliação de um jogo educacional de anatomia e fisiologia digestória humana. XV Simpósio Brasileiro de Games e Entretenimento DigitalSBGames, 288-294. [GS SEARCH]

Dörner, R., Göbel, S., Effelsberg, W., \& Wiemeyer, J. (2016). Serious Games. Springer International Publishing. DOI:https://doi.org/10.1007/978-3-319-40612-1 [GS SEARCH]

Eckardt, L., \& Robra-Bissantz, S. (2019). EGameFlow in a Serious Game: Gaming Experience with the Same Game Design but Different Learning Content. In PACIS (p. 103). [GS $\underline{\text { SEARCH] }}$

Fonseca, J. J. S. D., \& Fonseca, S. D. (2007). Didática geral. Fortaleza: FGF.

Fu, F. L., Su, R. C., \& Yu, S. C. (2009). EGameFlow: A scale to measure learners' enjoyment of e-learning games. Computers \& Education, 52(1), 101-112. DOI: https://doi.org/10.1016/j.compedu.2008.07.004 [GS SEARCH] 
Ijaz, K., Ahmadpour, N., Wang, Y., \& Calvo, R. A. (2020). Player experience of needs satisfaction (PENS) in an immersive virtual reality exercise platform describes motivation and enjoyment. International Journal of Human-Computer Interaction, 1-10. DOI:https://doi.org/10.1080/10447318.2020.1726107 [GS SEARCH]

Inchamnan, W. (2016). An Analysis of Creative Process Learning in Computer Game Activities through Player Experiences. IAFOR Journal of Education, 4(2), 119-139. [GS SEARCH]

Jegers, K. (2007). Pervasive game flow: understanding player enjoyment in pervasive gaming. $\begin{array}{llll}\text { Computers in } \quad \text { Entertainment } & \text { 9-es. }\end{array}$ DOI:https://doi.org/10.1145/1236224.1236238 [GS SEARCH]

Kiili, K., De Freitas, S., Arnab, S., \& Lainema, T. (2012). The design principles for flow experience in educational games. Procedia Computer Science, 15, 78-91. DOI:https://doi.org/10.1016/j.procs.2012.10.060 [GS SEARCH]

Klarkowski, M., Johnson, D., Wyeth, P., McEwan, M., Phillips, C., \& Smith, S. (2016, May). Operationalising and evaluating sub-optimal and optimal play experiences through challengeskill manipulation. In Proceedings of the 2016 CHI Conference on Human Factors in Computing Systems (pp. 5583-5594). DOI:https://doi.org/10.1145/2858036.2858563 [GS $\underline{\mathrm{SEARCH}}]$

Löbach, B. (2001). Design industrial. São Paulo: Edgard Blücher.

Machado, L. S., Valença, A. M. G., \& Morais, A. M. (2016). A serious game for education about oral health in babies. Tempus Actas de Saúde Coletiva, 10, 167-188. DOI:https://doi.org/10.18569/tempus.v10i2.1657 [GS SEARCH]

Ninaus, M., Moeller, K., McMullen, J., \& Kiili, K. (2017). Acceptance of Game-Based Learning and Intrinsic Motivation as Predictors for Learning Success and Flow Experience, 15-30. DOI:https://doi.org/10.17083/ijsg.v4i3.176 [GS SEARCH]

O'Brien, H. L., \& Toms, E. G. (2008). What is user engagement? A conceptual framework for defining user engagement with technology. Journal of the American Society for Information Science and Technology, 59(6), 938-955. DOI:https://doi.org/10.1002/asi.20801 [GS $\underline{\text { SEARCH] }}$

Przybylski, A. K., Rigby, C. S., \& Ryan, R. M. (2010). A motivational model of video game engagement. Review of general psychology, 14(2), 154-166. DOI:https://doi.org/10.1037\%2Fa0019440 [GS SEARCH]

Rigby, S., \& Ryan, R. (2007). The player experience of need satisfaction (PENS) model. Immersyve Inc.

Ryan, R. M., \& Deci, E. L. (2000). Self-determination theory and the facilitation of intrinsic motivation, social development, and well-being. American psychologist, 55(1), 68-78. DOI: https://doi.org/10.1037/0003-066X.55.1.68 [GS SEARCH]

Ryan, R. M., Rigby, C. S., \& Przybylski, A. (2006). The Motivational Pull of Video Games: A Self-Determination Theory Approach. Motivation and Emotion, 30(4), 344-360. DOI: https://doi.org/doi:10.1007/s11031-006-9051-8 [GS SEARCH]

Schell, J. (2014). The Art of Game Design: A book of lenses. AK Peters/CRC Press.

Sousa Pires, F. G., Michel, F., Bernardo, J. R. S., Melo, R., \& de Freitas, R. (2018). O livro do conhecimento: Um jogo de aventura para exercitar a ortografia. In Simpósio Brasileiro de Informática na Educação, 695-704. DOI:http://dx.doi.org/10.5753/cbie.sbie.2018.695 [GS $\underline{\text { SEARCH] }}$ 
Sweetser, P., Johnson, D., Wyeth, P., Anwar, A., Meng, Y., \& Ozdowska, A. (2017). GameFlow in different game genres and platforms. Computers in Entertainment (CIE), 15(3), 1-24. DOI:https://doi.org/10.1145/3034780 [GS SEARCH]

Sweetser, P., \& Wyeth, P. (2005). GameFlow: a model for evaluating player enjoyment in games. Computers in Entertainment (CIE), 3(3), 1-24. DOI: $\underline{10.1145 / 1077246.1077253}$ [GS $\underline{\text { SEARCH] }}$

Tamborini, R., Bowman, N. D., Eden, A., Grizzard, M., \& Organ, A. (2010). Defining media enjoyment as the satisfaction of intrinsic needs. Journal of communication, 60(4), 758-777. DOI:https://doi.org/10.1111/j.1460-2466.2010.01513.x [GS SEARCH]

Tsuda, M., Sanches, V. M., Ferreira, T. G., Otsuka, J. L., \& Beder, D. M. (2014). Análise de métodos de avaliação de jogos educacionais. Proceedings of XIII SBGames, 12-14. [GS $\underline{\mathrm{SEARCH}}]$

Whitton, N. (2010). Game Engagement Theory and Adult Learning. Simulation \& Gaming, 42(5), 596-609. DOI:https://doi.org/10.1177\%2F1046878110378587 [GS SEARCH]

Wilkinson, P. (2013). Affective educational games: Utilizing emotions in game-based learning. In 2013 5th International Conference on Games and Virtual Worlds for Serious Applications (VS-GAMES) (1-8). IEEE. DOI:https://doi.org/10.1109/VS-GAMES.2013.6624219 [GS $\underline{\text { SEARCH] }}$

Wouters, P., \& Van Oostendorp, H. (2017). Overview of instructional techniques to facilitate learning and motivation of serious games. In Instructional techniques to facilitate learning and motivation of serious games, 1-16. Springer, Cham. DOI: https://doi.org/10.1007/9783-319-39298-1_1 [GS SEARCH] 